4

5 Michael V. Schaefer ${ }^{a}$, Xinxin Guo ${ }^{b}$, Yiqun Gan $^{b}$, Shawn G. Benner ${ }^{c}$, Aron M. Griffin ${ }^{d}$, Christopher

\section{Redox Controls on Arsenic Enrichment and Release from Aquifer Sediments in Central Yangtze River Basin}

\section{(1)}

(1)
A. Gorski ${ }^{d}$, Yanxin Wang ${ }^{b^{*}}$, Scott Fendorf ${ }^{a *}$ ${ }^{a}$ Earth System Science Dept., Stanford University, Stanford, CA, USA ${ }^{\mathrm{b}}$ State Key Laboratory of Biogeology and Environmental Geology, China University of Geosciences, Wuhan, Hubei, P. R. China

${ }^{\mathrm{C} D e p a r t m e n t}$ of Geosciences, Boise State University, Boise, ID, USA

${ }^{\mathrm{d} C i v i l ~ a n d ~ E n v i r o n m e n t a l ~ E n g i n e e r i n g, ~ P e n n s y l v a n i a ~ S t a t e ~ U n i v e r s i t y, ~ U n i v e r s i t y ~ P a r k, ~ P A, ~ U S A ~}$

*Corresponding Authors

Email: fendorf@stanford.edu; yx.wang@cug.edu.cn 


\section{ABSTRACT}

19 More than 100 million people in Asia are presently exposed to groundwater with arsenic (As)

20 concentrations exceeding the World Health Organization standard of $10 \mu \mathrm{g} \mathrm{L}^{-1}$. Arsenic

21 contaminated groundwater within basins of the central portion of the Yangtze River has

22 recently been reported, but the processes controlling arsenic concentrations have yet to be

23 resolved. We examined the hydrologic and geochemical factors controlling arsenic within the

24 Jianghan Plain, an inland sedimentary basin of the Yangtze River, where arsenic concentrations

25 exhibit strong seasonal variability driven by surface and groundwater mixing (Schaefer et al.,

26 2016). Hydrologic fluctuations alter redox conditions in the aquifer, leading to oscillations

27 between arsenic/iron reduction and oxidation. Here we investigate the depth-distribution of

28 solid and aqueous phase iron and arsenic species and, through a series of laboratory

29 manipulations, constrain the biogeochemical processes controlling seasonal changes in

30 groundwater arsenic concentrations. In sediment incubations from $\sim 20 \mathrm{~m}$ below the surface,

31 where solid-phase arsenic concentrations exceed $100 \mathrm{mg} \mathrm{kg}^{-1}$, both unamended and glucose-

32 amended sediment samples result in arsenic release to the aqueous phase. In-situ carbon was

33 capable of promoting As release in the sediment. In contrast, sediment batch incubations from

34 other depths resulted in limited As release. Solid phase arsenic in the enriched zone was

35 relatively oxidized but may become reduced over short time periods. In sediments below the

36 As-enriched zone, glucose amendment resulted in arsenic reduction, but arsenic release to the

37 aqueous phase was restricted by the subsequent formation of arsenic sulfide minerals. Buried

38 sedimentary arsenic coupled with anaerobic microbial respiration of subsurface organic carbon

39 within the Jianghan Plain aquifer leads to rapid release of As to groundwater. Arsenic release 
40 from sediments at $\sim 20 \mathrm{~m}$ depth is sufficient to explain arsenic concentrations throughout the

41 aquifer, and provides a mechanism to explain how shifts in hydrology result in seasonally

42 variable arsenic concentrations in groundwater.

43 


\section{1. INTRODUCTION}

45 Deposition of arsenic-bearing sediments across floodplains leads to widespread geogenic

46 arsenic (As) contamination of South and Southeast Asian aquifers including the

47 Brahmaputra/Ganges, Mekong, and Red Rivers, encompassing Bangladesh and West Bengal,

48 India, Vietnam, and Cambodia where over 100 million people are at risk of As exposure

49 (Fendorf et al., 2010). Chronic exposure to As concentrations above the World Health

50 Organization (WHO) drinking water limit of $>10 \mu \mathrm{g} \mathrm{L}^{-1}$ increases the risk of a variety of ailments

51 including dermal lesions (Das et al., 2008), cancers (Steinmaus et al., 2000; Naujokas et al.,

52 2013), and neurological impairment (Wasserman et al., 2004; Wasserman et al., 2007). Current

53 estimates are that up to 19.6 million individuals are at risk of As exposure through drinking

54 water in China (Rodríguez-Lado et al., 2013).

55 Recent advances in statistical predictive models show promise in identifying As-affected areas

56 with sparse data (Rodríguez-Lado et al., 2013), but the regional scale of surface-feature based

57 statistical models is larger than the spatial variation of As concentrations, which can vary over

58 tens of meters (Michael, 2013). Although similarities exist between aquifer systems in Asia, no

59 comprehensive model exists that captures the complexity of when and where high As

60 concentrations occur across Asian aquifers. Reductive dissolution of As-containing iron oxides is

61 the predominant mechanism leading to elevated As concentrations in low-lying areas across

62 Asia (Nickson et al., 1998; Smedley and Kinniburgh, 2002), but As concentrations vary

63 significantly over small geographic regions (van Geen et al., 2003). Previous studies have

64 focused on identifying the relevant source of reactive organic carbon with reports of co-

65 deposited sedimentary carbon (Nickson et al., 2000; McArthur et al., 2004; Meharg et al., 2006) 
66 and surface-derived dissolved organic carbon (DOC) (Harvey et al., 2002; Mailloux et al., 2013)

67 serving as the relevant electron donor. However, reactions releasing As are limited by the

68 reactivity of Fe-oxide phases hosting As with respect to available reactive organic carbon for

69 microbial metabolism (Stuckey et al., 2016); it is now clear that the reactivity of both the

70 electron donor and acceptor must be considered to accurately model As release. Identifying

71 where within the sediment profile reactions mobilizing As occur and what limits these reactions

72 is important to predict the distribution of arsenic contamination and understand changes

73 induced by land-use change, groundwater extraction, and other perturbations on groundwater

74 As concentrations.

75 Seasonal variation in As concentrations makes avoiding As difficult, and although large

76 variations have not been widely observed, it is unclear whether this is due to lack of temporal

77 resolution in testing (i.e., a lack of retesting a single well in multiple seasons) or because As

78 concentrations do not generally vary with season (Cheng et al., 2005; Ayotte et al., 2015).

79 Within the Jianghan Plain of the Yangtze River Basin, As concentrations do vary seasonally

80 (Duan et al., 2015) resulting from changes in surface and groundwater interactions (Schaefer et

81 al., 2016). Increases and decreases in dissolved sulfide, Fe(II), and As concentrations occur over

82 periods of weeks to months as soluble, reduced species are oxidized following mixing of oxic

83 surface water with reduced groundwater; as oxidant supply diminishes the aquifer again

84 becomes reducing and concentrations increase (Schaefer et al., 2016).

85 We utilized a $\sim 10 \mathrm{~km}^{2}$ field area in the Jianghan Plain with seasonally variable chemistry to 86 assess whether Fe/As reduction is coupled to detrital (in situ) carbon or surface-derived carbon, 
87 or a combination of these sources. The carbon source may determine the time required to

88 observe changes in As concentrations linked to anthropogenic disturbances such as large-scale

89 groundwater extraction (Winkel et al., 2011) and pond excavation (Neumann et al., 2010). If the

90 relevant source of reduced carbon is surface-derived, the lag time to observe changes is

91 expected to be on the order of 100-1000 years assuming flow rates in pristine groundwater

92 systems (Benner et al., 2008) or on the order of decades with irrigation pumping (Harvey et al.,

93 2006). Conversely, if the relevant reduced carbon source is located at or near the depth of

94 water extraction, the lag time for changes in water chemistry to occur may be similar to

95 chemical reaction rates, which are on the order of hours to days, not dependent on advection

96 rates. We hypothesized that a buried source of As must exist at a depth near highly variable

97 groundwater As concentrations. Further, a carbon source reactive toward As and Fe in the

98 sediments must co-occur or be replenished seasonally in order for seasonal changes in As

99 concentrations to persist.

100 In the present study, we used a combination of field measurements, spectroscopic examination

101 of sediments, and an expanded set of laboratory incubations and extractions to determine the

102 reactions responsible for seasonal variation in aqueous As concentrations. Solid phase

103 chemistry in the sediment profile coupled with hydrologic changes explain the observed

104 seasonality in aqueous As concentrations. We also assess whether As in the sediment poses a

105 threat to groundwater quality under scenarios of changing aquifer conditions and place our

106 results from the Jianghan Plain in context with other arsenic-affected basins in China and South

107 and Southeast Asia. 


\section{2. Methods}

\section{$109 \quad 2.1$ Field Setting and Sampling Procedures}

\section{$110 \quad$ 2.1.1 The Jianghan Plain}

111 The Jianghan Plain is an inland river basin supplied with alluvial sediment from the Yangtze

112 River and Han River (a major tributary to the Yangtze). The $>55,000 \mathrm{~km}^{2}$ basin is located

113 downstream of the Three Gorges Dam and has a subtropical monsoon climate with hot, wet

114 summers and cold, dry winters. The field area for this study is a $\sim 10 \mathrm{~km}^{2}$ site within the

115 Jianghan Plain where land-use is mainly agricultural consisting of aquaculture ponds and upland 116 and flooded crops. Surface water levels at the site vary by 5-8 m annually while groundwater

117 levels fluctuate by $\sim 1 \mathrm{~m}$. These shifts lead to an annual switch between groundwater discharge

118 and recharge that drives seasonal As, Fe(II), and sulfide concentrations in the aquifer (Schaefer

119 et al., 2016). Hydrology in the field area is likely under the influence of human activity through

120 substantial construction of aquaculture ponds, diversion of surface water for irrigation canals,

121 and groundwater extraction for industrial and agricultural use. Further details of the field area

$122\left(30.15^{\circ} \mathrm{N}, 113.66^{\circ} \mathrm{E}\right)$ are provided in previous publications (Gan et al., 2014; Duan et al., 2015;

123 Schaefer et al., 2016).

\section{$124 \quad 2.1 .2$ Well Installation}

125 Drilling occurred in November 2011 and sediment cores were collected during well installation

126 using a Geoprobe 6620DT direct push drill rig (0-20 m depth) or every $3 \mathrm{~m}$ using a rotary drill

127 method (20-50 m depth). Immediately after cores were brought to the surface, they were

128 sectioned into $20 \mathrm{~cm}$ lengths, capped, and placed into anaerobic boxes with oxygen scavenging 
129 packs (AnaeroPack, Mitsubishi, Japan). Samples were then frozen and shipped to Stanford

130 University, where they remained frozen until further analysis. Subsamples used for bulk analysis

131 and acid extractions were thawed and dried in an anoxic chamber (95\%:5\% $\mathrm{N}_{2}: \mathrm{H}_{2},<1$ ppm $\mathrm{O}_{2}$ )

132 and homogenized by manual grinding. Sediments used for incubations were thawed and added

133 to reaction vessels without drying. Dry mass was calculated by determining the water content

134 of samples by weighing samples before and after drying, and all reported values are referenced

135 to dry sample mass.

\section{$136 \quad 2.2$ Sediment Analysis}

\section{2.2.1 Bulk Characterization}

138 The bulk elemental composition of samples was determined using energy dispersive $\mathrm{x}$-ray

139 fluorescence (ED-XRF) spectroscopy (Spectro Xepos). Between 1.5 and $2 \mathrm{~g}$ of ground sediment

140 was placed in a plastic cup fitted with a thin layer of polypropylene Prolene film (Chemplex). X-

141 rays were generated with a 50-watt $x$-ray tube and fluorescent $x$-rays were detected on five

142 energy targets to cover the elemental range from sodium to uranium. Measurements were

143 performed in a He atmosphere to minimize x-ray attenuation. Bulk elemental abundance was

144 calculated based on the intensity of the characteristic fluorescent x-rays of each element.

145 Carbon and nitrogen contents were determined by placing 19 to $20 \mathrm{mg}$ of dry, finely ground

146 sediment in a small tin and combusting at $1060^{\circ} \mathrm{C} . \mathrm{N}_{2}$ and $\mathrm{CO}_{2}$ gas were measured post-

147 combustion on a Carlo Erba Elemental Analyzer. Carbon and nitrogen analyses were performed 148 in duplicate.

149 2.2.2 Iron and Arsenic X-ray absorption spectroscopy 
150 X-ray absorption spectroscopy (XAS) was used to probe the local chemical environment of As

151 and Fe in sediments recovered from the field area. Arsenic K-edge x-ray absorption near-edge

152 structure (XANES) spectroscopy was used to differentiate arsenate, arsenite, and arsenic sulfide

153 species. Iron K-edge extended X-ray absorption fine structure (EXAFS) spectroscopy was used to

154 apportion the Fe pool into mineralogical classes. Both As XANES and Fe EXAFS spectra were

155 collected at beamline 11-2 at the Stanford Synchrotron Radiation Lightsource (SSRL).

156 Dried subsamples of selected cores were suspended in deoxygenated deionized (DDI) water,

157 and the suspension was filtered onto cellulose filter paper (Whatman). Samples from batch

158 incubations (details in section 2.3) were filtered directly from incubation suspensions but

159 otherwise treated the same. Reference standards were prepared by diluting and homogenizing

160 powdered reference material with boron nitride to minimize self-absorption. Three to seven

161 scans were collected for each sample and averaged. Background subtraction, normalization,

162 and fitting were performed with the IFEFFIT routine in Athena (Ravel and Newville, 2005).

163 Energy was tuned with a double crystal Si(220) monochromator and fluorescent x-rays were

164 detected with either a 30- or 100-element solid-state Ge detector. Incident X-ray intensity (Io)

165 was measured via an in-line ionization detector and all reported intensities are relative to lo.

166 Higher-order harmonics were minimized with harmonic rejection mirrors, and the

167 monochromator was typically detuned $\sim 30 \%$.

168 Arsenic K-edge XANES spectra were collected by scanning from 11635 to $12290 \mathrm{eV}$ in 6 eV steps

169 except from $11840-11900 \mathrm{eV}$, where the step size was reduced to $0.3 \mathrm{eV}$. Energy was calibrated

170 to the top of the white line of sodium arsenate (11874 eV). Linear combination fitting was 
171 performed in the range $11842-11922 \mathrm{eV}$ on both normalized absorbance spectra and the first-

172 derivative of As XANES data using standards of arsenian pyrite (Stanford Mineral Collection),

$173 \mathrm{H}_{\mathrm{x}} \mathrm{AsO}_{3}{ }^{3-x}$ adsorbed on ferrihydrite, and $\mathrm{H}_{\mathrm{x}} \mathrm{AsO}_{4}{ }^{3-\mathrm{x}}$ adsorbed on ferrihydrite.

174 Iron K-edge EXAFS spectra were collected by scanning from 6880 to $8012 \mathrm{eV}$ to generate $\mathrm{k}$ -

175 space data in the range $0-15.3 \AA^{-1}$. Energy was calibrated to the K-edge of Fe foil and set to

$1767111 \mathrm{eV}$. Iron spectra were fit using the Fe EXAFS $(\chi)$ function over a k range $3-12 \AA^{-1}$ using

177 linear combination fitting to minimize the least squares function. Fitting was restricted to the

178 use of four components per spectrum. Standards used for Fe EXAFS fits included ferruginous

179 smectite (SWa-1, Source Clay Mineral Repository); glaucophane, hornblende, and biotite

180 (Stanford Mineral Collection); and ferrihydrite-, goethite-, and hematite-coated sands.

\section{$181 \quad$ 2.2.3 Carbon NEXAFS Spectroscopy}

182 Carbon near-edge X-ray absorption fine structure (NEXAFS) spectroscopy was performed at the

183 Canadian Light Source (CLS) on the spherical grating monochromator (SGM) beamline to

184 determine the chemical speciation of $\mathrm{C}$ within native sediments. Samples were affixed to a

185 copper holder using carbon tape and transferred into the beam line vacuum chamber $\left(\sim 10^{-}\right.$

$186{ }^{7}$ torr). Fluorescent X-rays were detected using silicon drift detectors (SDD, Amptek).

187 Samples were scanned from $270-320 \mathrm{eV}$ in continuous (fast) scan mode. Each scan lasted

$18860 \mathrm{~s}$ and $25-40$ scans were collected per sample. The beam was moved to a fresh area of the

189 sample between each scan to minimize beam damage. Individual scans were summed to

190 provide a single spectrum for each sample, and energy was calibrated using citric acid.

191 Each calibrated spectrum was normalized by dividing by the scattering spectrum of blank 
192 gold foil (average of $>300$ scans) in aXis software (Hitchcock et al., 2012). Normalized,

193 calibrated spectra were then imported to Athena (Ravel and Newville, 2005) where pre-

194 and post-edge normalization was performed prior to peak fitting with Gaussian and 195 arctangent functions.

\subsubsection{Mössbauer Spectroscopy}

197 Mössbauer transmission spectra were collected to determine the relative ratios of $\mathrm{Fe}(\mathrm{II})$ and

$198 \mathrm{Fe}(\mathrm{III})$ species in sediment samples, as well as to differentiate $\mathrm{Fe}$ (III) oxides and Fe(III) bound in

199 silicate minerals. Samples were prepared by mounting anoxic sample between two pieces of 5

200 mil Kapton tape inside an anaerobic glovebox. Measurements were performed using a SVT-400

201 Mössbauer system (SEE Co., USA). Spectra were collected at $20 \mathrm{~K}$ to ensure Fe-oxides achieve

202 magnetic ordering (so they manifest as a sextet feature) but to also avoid magnetic ordering of

203 Fe in silicate minerals, allowing unambiguous differentiation of each component. Although we

204 cannot rule out the possibility of Fe-oxides ordering below $20 \mathrm{~K}$ or silicates ordering above $20 \mathrm{~K}$,

205 our fitting represents the most likely scenario. Spectra were calibrated relative to $\alpha$-Fe(0) foil

206 and fit with Recoil software using a Voigt-based model (Rancourt and Ping, 1991). We assume

207 consistent recoilless fractions in each sample so that relative areas of fitted components are

208 proportional to the relative abundance of each component.

\section{$209 \quad 2.3$ Aqueous Analyses}

$210 \quad$ 2.3.1 Field Samples

211 Prior to sampling, wells in the field area were purged and temperature $\left( \pm 0.1^{\circ} \mathrm{C}\right)$, conductivity

$212\left( \pm 1 \mu \mathrm{S} \mathrm{cm}^{-1}\right), \mathrm{pH}( \pm 0.01)$ and oxidation-reduction potential (ORP, $\left.\pm 0.1 \mathrm{mV}\right)$ were measured in 
213 the field using a Hach HQ40D multimeter. ORP was converted to Eh by adding $+240-251 \mathrm{mV}$

214 depending on the water temperature. Samples were acidified in the field, and arsenic

215 concentrations were measured using a Titan 930 hydride generation atomic fluorescence

216 spectrophotometer (HG-AFS) with a detection limit of $0.05 \mu \mathrm{g} \mathrm{L}^{-1}$. Manganese concentrations

217 were determined by inductively coupled plasma atomic emission spectrometry (ICP-AES, IRIS

218 Intrepid II XSP) with a detection limit of $0.1 \mathrm{mg} \mathrm{L}^{-1}$. Aqueous Fe(II) and sulfide concentrations

219 were measured in the field using a Hach 2800 portable spectrophotometer and Hach reagent 220 kits.

221 2.3.2 Laboratory Samples

222 Major elements from acid extractions were measured by inductively coupled plasma optical

223 emission spectroscopy (ICP-OES, Thermo ICAP 6300). Aqueous Fe(II) speciation was performed

224 using an adapted version of the 1,10 phenanthroline method (Tamura et al., 1974). Briefly,

225 samples were diluted (if necessary) until the final Fe concentration was $<100 \mu \mathrm{M}$. Each sample

226 was split for Fe(II) and total Fe analysis. The total Fe sample was reduced with hydroxylamine-

$227 \mathrm{HCl}$ prior to chromaphore addition; 1,10 phenanthroline was then added in excess to both

228 samples, and the $\mathrm{pH}$ was buffered at $\sim 3$ with ammonium acetate prior to measurement at 510

$229 \mathrm{~nm}$ on a spectrophotometer. Good agreement $(<5 \%$ difference in 7 of 11 samples, all samples

$230<30 \%$ difference) was observed for total Fe measured by 1,10-phenanthroline and ICP-OES

231 (Electronic Annex, Figure EA-1).

\section{$232 \quad 2.4$ Batch Experiments}

\section{2.4.1 Sediment Incubations}


234 Sediment microcosms were performed in duplicate to track arsenic release under unamended

235 and glucose amended conditions. $20 \mathrm{~g}$ of anoxic sediment was suspended in $100 \mathrm{~mL}$ of an

236 anoxic solution containing $2 \mathrm{mM}$ glucose or DDI water. Aliquots $(5 \mathrm{~mL})$ of homogenized

237 sediment-water slurry were sampled daily for $4 \mathrm{~d}$ and filtered with a $0.2 \mu \mathrm{m}$ pore membrane

238 after which major elements were measured with ICP-OES. Following the aqueous sampling

239 period, the incubations were left in the anoxic chamber undisturbed for $30 \mathrm{~d}$ until solids were

240 removed for XAS analysis as described in Section 2.2.2.

\section{2.4.2 Chemical Extractions}

242 Chemical extractions of sediments were performed to evaluate the reactivity of As in sediment

243 from various depths. $\mathrm{HCl}$ extractions were performed in triplicate on anoxic sediment samples

244 by weighing $100 \mathrm{mg}$ of sediment into a $15 \mathrm{~mL}$ centrifuge tube and adding $12 \mathrm{~mL}$ of $2 \mathrm{M} \mathrm{HCl}$

245 (trace metal grade). Reactors were shaken for $\sim 20 \mathrm{~h}$, then filtered $(0.2 \mu \mathrm{m})$ and diluted with DI

246 water. Major elements were measured by ICP-OES, and Fe(II) and total Fe were measured on a

247 spectrophotometer using the 1,10 phenanthroline method (Tamura et al., 1974). 


\section{RESULTS}

\section{$250 \quad 3.1$ Aqueous Chemistry}

251 Groundwater within the field area (Duan et al., 2015), and throughout the Jianghan Plain (Gan

252 et al., 2014), is contaminated with As; within the field area we examined, wells screened at 10,

253 25, and $50 \mathrm{~m}$ average $65 \mu \mathrm{g} \mathrm{L}^{-1}$ As between May 2012 and December 2014 (Table 1) and every

254 well in the field area recorded at least one measurement above $10 \mu \mathrm{g} \mathrm{L}^{-1}$ during the sampling

255 period. Arsenic concentrations vary seasonally with periods of groundwater recharge and

256 discharge, reaching $>1000 \mu \mathrm{g} \mathrm{L}^{-1}$ and $<200 \mu \mathrm{g} \mathrm{L}^{-1}$ annually at the well where sediment was

257 collected (Figure 1). Iron and Mn concentrations average 5.1 and $1.3 \mathrm{mg} \mathrm{L}^{-1}$, respectively, while

258 sulfide concentrations average $39 \mu \mathrm{g} \mathrm{L}^{-1}$. The $\mathrm{pH}$ ranges from $6-8$, with an average of 7.1. The

259 coupling of increases and decreases in dissolved Fe(II) and As concentrations at the field area

260 (Figure 1) indicates that both reductive dissolution and oxidative (re)precipitation of As-

261 containing Fe-oxides control As concentrations in the aquifer (Schaefer et al., 2016).

\section{$262 \quad 3.2$ Sediment Characterization}

\section{$263 \quad$ 3.2.1 Bulk Sediment Properties and Chemistry}

264 Texture analysis of recovered borehole sediment showed a sedimentary history similar to many

265 large Asian deltas (Smedley and Kinniburgh, 2002), including a clay and silt cap overlying sand

266 deposits with distributed clay lenses/layers (Figure 2). The stratigraphy is similar to other

267 boreholes in the Jianghan Plain (Zhang et al., 2008), where the top $20 \mathrm{~m}$ is composed of clay

268 and silt deposits, and from 20-50 m (maximum depth of this study) lies a sandy aquifer with 
269 interbedded clay and silt layers. Deeper clay layers (Figure 2) split the sand deposits into locally

270 distinct aquifers in some areas, although similar water level measurements in 25 and $50 \mathrm{~m}$ wells

271 are observed in nested wells across the field area indicating a continuous and/or connected

272 aquifer at the regional $(\mathrm{km})$ scale (Schaefer et al., 2016).

273 Solid-phase As concentrations in the sediment profile average $12.7 \mathrm{mg} \mathrm{kg}^{-1}$ but reach $>100 \mathrm{mg}$

$274 \mathrm{~kg}^{-1}$ in a zone of As enrichment between $\sim 18-20 \mathrm{~m}$ below ground level (Figure 2, Table 2). This

275 zone is coincident with low sediment carbon (18-20 m range $0.4-2.6 \mathrm{~g} \mathrm{~kg}^{-1}, 0-51 \mathrm{~m}$ average 10.3

$\left.276 \mathrm{~g} \mathrm{~kg}^{-1}\right)$ and sulfur (18-20 $\mathrm{m}$ range $12-52 \mathrm{mg} \mathrm{kg}^{-1}, 0-51 \mathrm{~m}$ average $\left.591 \mathrm{mg} \mathrm{kg}^{-1}\right)$. Bulk Fe

277 concentrations average $37 \mathrm{~g} \mathrm{~kg}^{-1}$ through the profile and range from $9.4-61.2 \mathrm{~g} \mathrm{~kg}^{-1}$ (Table 2).

\section{3.2.2 Solid-phase Arsenic Speciation}

279 Arsenic K-edge XANES analysis of sediment samples reveals that As exists predominantly as

$280 \mathrm{H}_{\mathrm{x}} \mathrm{AsO}_{4}{ }^{3-\mathrm{x}}$ near the land surface ( $85 \% \mathrm{As}(\mathrm{V})$ at $1.5 \mathrm{~m}$ depth), but As speciation is dominated by a

281 combination of $\mathrm{H}_{\mathrm{x}} \mathrm{AsO}_{3}{ }^{3-\mathrm{x}}(\mathrm{As}(\mathrm{III})$ ) and As-sulfide phases from 3-18 $\mathrm{m}$ depth (Figure 2, Figure 3,

282 Table 3). At $18.7 \mathrm{~m}$ depth, bulk As content increases and As speciation switches to being

283 dominated by $\mathrm{H}_{\mathrm{x}} \mathrm{AsO}_{4}{ }^{3-\mathrm{x}}(82 \% \mathrm{As}(\mathrm{V}))$. Below the $18-20 \mathrm{~m}$ oxidized zone, reduced As phases

284 again dominate (Figure 2). Arsenic sulfides present in sediments likely result from incorporation 285 of As in authigenic Fe-sulfide minerals (Lowers et al., 2007).

286 3.2.3 Solid-phase Iron Speciation 
288 Mössbauer spectroscopic analysis of sediments reveals that Fe exists in a combination of

289 phases at each depth analyzed; they can, however, be represented effectively by three phases:

$290 \mathrm{Fe}(\mathrm{II})$, silicate-bound Fe(III), and goethite/Fe-oxide (Figure 4, Table EA-1). Fe(II) spectral

291 parameters are indicative of Fe(II) in primary minerals such as chlorite and talc (Blaauw et al.,

292 1980), in reduced secondary silicates such as smectite (Schaefer et al., 2011), or Fe"l sorbed on

293 mineral surfaces such as aluminum oxide or clays (Gehin et al., 2007; Larese-Casanova et al.,

294 2010). Goethite was used as a representative Fe-oxide, and Mössbauer spectral parameters are

295 consistent with goethite in each of the samples. Fe(III)-silicate minerals are assigned on the

296 basis of an unordered Fe(III) doublet at $20 K$ (Murad and Cashion, 2004). Iron in oxidized

297 sediment near the surface (Figure 4 ) is a mix of each of these phases, but $\sim 40 \%$ of the Fe pool

298 exists as Fe-oxide. In the relatively oxidized As-enriched zone (18-20 m), Fe-oxides are similarly

299 abundant. From $18 \mathrm{~m}$ and below, the proportion of Fe-oxides decreases and a concomitant

300 increase in $\mathrm{Fe}(\mathrm{II})$ is observed, while $<5 \%$ change is observed in the $\mathrm{Fe}$ (III)-silicate fraction

301 through the sediment profile.

\subsubsection{Iron EXAFS Spectroscopy}

303 EXAFS spectra were collected to determine the speciation of Fe phases in sediments.

304 Comparison of Fe EXAFS spectra (Figure 5) shows changes in Fe mineral phase through the

305 depth profile, and Fe mineralogy is closely linked to As dynamics in the aquifer (Figure 2).

306 Surface sediments $(1.5 \mathrm{~m}$ ) contain $\sim 30 \%$ (EXAFS) to 40\% (Mössbauer) of the Fe within Fe(III)

307 oxides. The reduced zone below this depth ( $2.5 \mathrm{~m}$ and $7.1 \mathrm{~m}$ samples) contains $\mathrm{Fe}$ in silicate

308 minerals, consistent with the instability of Fe-oxides under strong reducing conditions. Between 
30918 and $23 \mathrm{~m}$ depth, $25-50 \%$ of sediment Fe exists as oxides, consistent with more oxidized

310 conditions at these depths. At $31 \mathrm{~m}$ depth a small amount of Fe sulfide (7\%) improved linear

311 combination fit results and is consistent with higher total sulfur content at this depth. However,

312 Mössbauer results did not indicate the presence of Fe sulfides. Results of Fe EXAFS

313 spectroscopy are generally consistent with results from Mössbauer spectroscopy (Figure 4,

314 Figure 5, Table EA-1, Table EA-2).

315 3.2.4 Carbon NEXAFS Spectroscopy

316 Carbon 1s NEXAFS spectroscopy was used to probe the chemical speciation of carbon in aquifer

317 sediments (Figure 6a). Spectra from all depths exhibit features generally observed in NEXAFS

318 spectra of soil/sediment organic matter (SOM) including resonances indicating the presence of

319 aromatic, phenolic, aliphatic, and carboxyl functional groups (Schumacher et al., 2005; Kleber et

320 al., 2011). In all samples, a peak is observed at $285 \mathrm{eV}$ indicative of aromatic C, whereas the

321 shoulder feature at $287.5 \mathrm{eV}$ indicates the presence of aliphatic compounds. The peak at $\sim 288.5$

$322 \mathrm{eV}$ indicates amide and carboxylate $\mathrm{C}$. The peak at $290.3 \mathrm{eV}$, most prominent in the spectrum

323 from $43.5 \mathrm{~m}$, indicates the presence of carbonyl groups. The ratio of the intensity of peaks at

324285 and $288.5 \mathrm{eV}$ provides an indication of the relative aromaticity of the carbon in the sample

325 (Kleber et al., 2011). The 285/288.5 peak ratio increases from 0.33 at $1.5 \mathrm{~m}$ to 0.47 at $17.9 \mathrm{~m}$

326 before decreasing to 0.28 between 20 to $23 \mathrm{~m}$ (Figure $6 \mathrm{~b}$ ). The decrease in peak ratio indicates

327 a decrease in relative aromaticity of the carbon at these depths. In general, spectra throughout

328 the profile are indicative of $\mathrm{C}$ in microbial biomass.

\section{$329 \quad 3.3$ Batch Incubations and Extractions}


330 To determine the potential for As partitioning from solid to aqueous phase over the sediment

331 depth profile, we conducted batch incubations with DDI water or $2 \mathrm{mM}$ glucose, as well as

332 chemical extractions with $2 \mathrm{M} \mathrm{HCl}$. When sediment is suspended in anoxic DDI water, arsenic is

333 released from solids of the As-enriched zone at $20 \mathrm{~m}$ depth, but As release is limited at all other

334 depths (Figure 7). The rate of As release in DDI water from sediments of $20 \mathrm{~m}$ depth is initially

335 rapid, with $70 \%$ of net As release occurring within the first day of incubation (Figure EA-2,

336 Figure EA-3). By day 4 of the incubation, $10 \%$ of total solid-phase As (Figure EA-4), or $11.4 \mu \mathrm{g}$ As

$337 \mathrm{~g}^{-1}$, was released from the 20-m sediments in DDI. Total carbon is low at this depth (Figure 7,

338 Table 2); accordingly, we tested (1) whether desorption is dominantly driven by chemically or

339 biologically mediated processes and (2) whether arsenic release is limited by the reactivity of in

340 situ carbon and Fe/As oxides.

341 Sediment incubations with $2 \mathrm{mM}$ glucose resulted in $24.4 \mu \mathrm{g} \mathrm{As} \mathrm{g}{ }^{-1}$ (23\%) released from $20 \mathrm{~m}$ -

342 depth sediment, but similar to DDI incubations, $<1 \mu \mathrm{g} \mathrm{As} \mathrm{g}^{-1}(<4 \%)$ was released from

343 incubation of sediments from all other depths (Figure 7). Over a 4 d incubation, glucose

344 addition enhanced As desorption approximately 2-fold compared to incubations with DDI water

345 (Figure 7). Arsenic release rates in the presence of glucose were more extensive and over an

346 extended time-period compared to DI water (Figure EA-2).

347 Sediment extractions with $2 \mathrm{M} \mathrm{HCl}$ liberate $58 \mu \mathrm{g} \mathrm{As} \mathrm{g}^{-1}$ from 20 m-depth sediment,

348 approximately half of the $107 \mu \mathrm{g} \mathrm{As} \mathrm{g}^{-1}$ (Figure 2, Table 2). This amount exceeds As release

349 observed in incubations with glucose by approximately 2 -fold. Arsenic release from $\mathrm{HCl}$ 
350 extractions has a similar trend over the depth profile to the incubations with glucose and DDI,

351 but $\mathrm{HCl}$ extractions released more As, especially in near-surface sediments (Figure 7).

\section{$352 \quad 3.4$ XAS Analysis of Incubated Sediment}

353 Sediments incubated with glucose were analyzed by As K-edge XANES spectroscopy to evaluate

354 changes in As speciation post-incubation (Figure 3). Glucose addition stimulates net reduction

355 of As at all depths, as indicated by a net decrease in the arsenate fraction in all incubated

356 samples (Figure 8). At depths with limited bulk carbon and sulfur ( $18-25 \mathrm{~m}$ ), solid phase As

357 transitions from $\mathrm{H}_{\mathrm{x}} \mathrm{AsO}_{4}{ }^{3-\mathrm{x}}$ to $\mathrm{H}_{\mathrm{x}} \mathrm{AsO}_{3}{ }^{3-\mathrm{x}}$ after glucose addition, which promotes As desorption

358 (Kocar et al., 2006; Tufano et al., 2008). We also observed transformation of $\mathrm{H}_{\mathrm{x}} \mathrm{AsO}_{3}{ }^{3-\mathrm{x}}$ and

$359 \mathrm{H}_{\mathrm{x}} \mathrm{AsO}_{4}{ }^{3-x}$ moieties to arsenic sulfide in sediments from 7, 31, and $43 \mathrm{~m}$ depth (Figure 8, Table 3).

360 At these depths, glucose addition does not stimulate As release to the aqueous phase (Figure

361 7), but instead causes a transformation to As-sulfides (Figure 8, Table 3), sequestering As in the

362 solid phase.

363 Batch incubation of sediment with glucose causes reduction of $\mathrm{H}_{\mathrm{x}} \mathrm{AsO}_{4}{ }^{3-\mathrm{x}}$ to $\mathrm{H}_{\mathrm{x}} \mathrm{AsO}_{3}{ }^{3-x}$ in

364 sediment retrieved from both $1.5 \mathrm{~m}$ and $20 \mathrm{~m}$ depths. Both sediments have carbon content $<8$

$365 \mathrm{~g} \mathrm{~kg}^{-1}$ and sulfur content $<100 \mathrm{mg} \mathrm{kg}^{-1}$; the arsenic content varies by nearly an order of

366 magnitude from $12 \mathrm{mg} \mathrm{kg}^{-1}$ at $1.5 \mathrm{~m}$ to $107 \mathrm{mg} \mathrm{kg}^{-1}$ at $20 \mathrm{~m}$. Initially, sediment from $1.5 \mathrm{~m}$-depth

367 has $85 \% \mathrm{H}_{\mathrm{x}} \mathrm{AsO}_{4}{ }^{3-\mathrm{x}}$, which decreases to $35 \% \mathrm{H}_{\mathrm{x}} \mathrm{AsO}_{4}{ }^{3-\mathrm{x}}$ at the end of incubation; likewise, the 20

368 m-depth sample decreases from $53 \%$ to $22 \% \mathrm{H}_{\mathrm{x}} \mathrm{AsO}_{4}{ }^{3-x}$ after glucose incubation (Table 3).

369 Arsenic sulfides were not detected by XANES analysis of either of these samples before or after

370 glucose amendment (Table 3). Release of arsenic to the aqueous phase differed between 
371 sediments from these two depths despite similar net reduction of As. Sediment collected from

$3721.5 \mathrm{~m}$ released $0.2 \mu \mathrm{g} \mathrm{As} \mathrm{g}^{-1}$ sediment (1.4\% arsenic released) while the $20 \mathrm{~m}$ sample released

$373 \sim 100$ times more arsenic, $24.4 \mu \mathrm{g} \mathrm{As} \mathrm{g}^{-1}$ (23\%), during incubation with glucose amendment

374 (Figure 7).

375 


\section{DISCUSSION}

\subsection{Controls on Arsenic Dissolution and Mobilization}

378 Seasonal incursions of oxic surface water to the subsurface decrease groundwater As

379 concentrations for 1-3 months annually. Rapid cycles in As concentrations are plausible in the 380 presence of a deep source of As and a reaction pathway that can rapidly transfer As between 381 solid and aqueous phases. The combination of a deep $(20 \mathrm{~m})$ sedimentary source of Fe-oxides

382 and As with a C source that is reactive toward Fe and As reduction provides such a pathway.

383 Arsenic release occurred from sediments approximately $20 \mathrm{~m}$ below the ground surface (Figure

384 7), coincident with peak dissolved As concentrations measured in the aquifer (Schaefer et al.,

385 2016). Periods of surface water recharge coincide with low groundwater As concentrations via

386 introduction of an oxidant during recharge; upon gradient reversal to groundwater discharge,

387 and the cessation of oxidant delivery to the subsurface, anoxic conditions dominate along with

388 elevated As concentrations (Schaefer et al., 2016). The rapid changes in As concentration within

389 the Jianghan plain suggest that As cycling is occurring at depths proximal to the screened wells

390 at $25 \mathrm{~m}$. Sediment at well-depths with the highest dissolved As concentrations ( $20 \mathrm{~m}$ depth) in

391 the Jianghan plain contains $>100 \mathrm{mg} \mathrm{As} \mathrm{kg}^{-1}$ and provides a potential source of As.

392 Sediments at $\sim 20 \mathrm{~m}$ depth contained oxidized Fe(III) and As(V) (Figure 2 ) and $\sim 0.2 \%$ carbon

393 (Figure 7, Table 2) at the time of sediment coring. Iron(III) oxides account for $25-40 \%$ of the Fe

394 pool between 18-23 m (Figure 4, Figure 5, Table EA-1, Table EA-2) and likely concentrate arsenic 395 at this depth through the formation of arsenate/arsenite surface complexes (Waychunas et al.,

396 1993; Fendorf et al., 1997; Dixit and Hering, 2003). Water in contact with oxidized sediments 
397 containing Fe(III) oxides generally exhibits low dissolved arsenic concentrations due to the high

398 affinity of arsenic oxoanions for Fe(III) mineral surfaces (Fendorf et al., 1997; Dixit and Hering,

399 2003). However, under Fe reducing conditions, As-bearing Fe(III) oxides undergo reductive

400 dissolution, releasing As to the aqueous phase (Nickson et al., 2000; Islam et al., 2004; Pedersen

401 et al., 2006; Tufano and Fendorf, 2008). A seasonal change to anoxic groundwater appears to

402 induce reductive dissolution of arsenic from the Fe(III) oxide hosts.

403 The extent of As release from sediment is controlled by reduction of Fe(III) and $\mathrm{As}(\mathrm{V})$ (Nickson

404 et al., 1998; Islam et al., 2004; Fendorf et al., 2010), but whether As-mobilizing reactions occur

405 is dependent on both the Fe/As phase and organic matter available (Stuckey et al., 2016). Batch

406 incubations of Jianghan Plain sediment show that at $20 \mathrm{~m}$ depth, As is transferred to the

407 aqueous phase upon onset of anaerobic conditions without the need for an exogenous electron

408 donor (Figure 7). Arsenic release occurs on the timescale of hours to days (Figure EA-2, Figure

409 EA-3), which supports field data showing arsenic concentrations changing over weeks to

410 months (Figure 1). Detrital carbon is reactive toward As host minerals at these depths. Carbon

411 NEXAFS analysis indicates that organic matter co-located with As-enriched sediments (20-23 m)

412 is more oxidized than adjacent sediments as indicated by a higher $288 / 285 \mathrm{eV}$ peak ratio

413 (Figure 6). LaRowe and Van Cappellen illustrated through a thermodynamic analysis that

414 oxidized $\mathrm{C}$ is more easily metabolized in anaerobic environments than relatively reduced $\mathrm{C}$

415 compounds (LaRowe and Van Cappellen, 2011). The relatively oxidized C co-located with

416 abundant sediment As could more effectively fuel Fe(III) reduction and As release compared to

417 relatively reduced C compounds in adjacent sediments. Addition of electron donor (glucose)

418 doubles the amount of As released to solution through (further) microbial reduction of $\mathrm{As}(\mathrm{V})$ 
419 and Fe(III)-oxides (Figure 7); these reductive processes are known to be key drivers of As

420 transfer from the solid to aqueous phase (Kocar et al., 2006; Tufano and Fendorf, 2008; Tufano

421 et al., 2008). These results show that As release from sediment (of 20-m depth) is possible on

422 the order of hours to days under simulated field conditions with or without addition of an

423 exogenous carbon source for microbial respiration.

424 Although $\sim 10 \mu \mathrm{g} \mathrm{g}^{-1}$ As is released from $20 \mathrm{~m}$ sediment without the addition of a reduced

425 carbon source, glucose addition doubles the amount of As released (Figure 7). Sediments from

426 all depths that were amended with glucose undergo net reduction (Figure 7), but As release is

427 limited to the near-surface and $\sim 20$ m sediments (Figure 7). Arsenic release in near-surface

428 sediments may provide a sustained source of As to the aquifer while As (along with $\mathrm{Fe}$ ) in the

429 subsurface may be cycled between oxidized (insoluble) and reduced (soluble) phases. Increased

430 As release with glucose addition implies that while carbon addition is not a prerequisite for As

431 release (at the 1.5 and 20 m depths), the sediments could respond to inputs of DOC to the

432 subsurface by releasing additional As through stimulated microbial reduction.

433 The depth of maximum bulk As concentration ( $20 \mathrm{~m})$ also results in the largest As release, but

434 even on a mass-normalized basis the sediments at 20-23 m release 3-5 times more As than any

435 other depth measured (Figure EA-4). In contrast, arsenic release from deep sediments does not

436 occur in sediment incubations from the Mekong Delta (Stuckey et al., 2016). Similarly, a lack of

437 As release without carbon amendment has also been observed in Bangladesh sediment

438 incubations from $13 \mathrm{~m}$ (Islam et al., 2004) and 43 m depths (Dhar et al., 2011). In West Bengal,

439 organic leaching from peat layers has been postulated to supply $\mathrm{C}$ utilized in Fe-oxide 
440 reduction, releasing As to the aqueous phase (McArthur et al., 2004). However, we did not

441 observe peat deposits in the shallow aquifer of the Jianghan Plain and sediment C content is

442 less than $3 \%$ throughout the sediment profile (Table 2).

4434.2 Impacts on Seasonally Variable Arsenic Concentrations

444 Seasonal variation in groundwater As concentrations have not been reported for Bangladesh

445 (Cheng et al., 2005) or West Bengal, India (McArthur et al., 2010), and seasonal variations are

446 restricted to wells proximal to the Mekong River in Cambodia (Polizzotto et al., 2008). Within

447 the noted systems of Bangladesh/West Bengal and Cambodia, recharge through fine-grained

448 surface sediments means that transport of As and/or DOC from the surface to the aquifer is on

449 the order of 10-100 years under natural conditions (Benner et al., 2008; Richards et al., 2016;

450 Lawson et al., 2016) or on the order of decades with irrigation or other large-scale pumping

451 (Harvey et al., 2006). Fracture flow has also been implicated in increasing infiltration rates

452 through impermeable clay layers by two orders of magnitude in Bangladesh (Stahl et al., 2014).

453 These previously measured flow rates are incompatible with the seasonal changes in

454 groundwater arsenic concentrations observed in the Jianghan Plain (Schaefer et al., 2016).

455 A deep sediment zone with high solid-phase As and a carbon source capable of providing

456 electrons for As and Fe reduction would yield conditions suitable for rapid seasonal shifts in As

457 concentrations in the aquifer-provided an oxidant is also seasonally supplied to the aquifer.

458 During periods of groundwater discharge, reducing conditions prevail and As is released from

459 buried sediments causing an increase in dissolved As concentrations (Figure 9B). When water 
460 levels change and groundwater recharge occurs, an oxidant $\left(\mathrm{O}_{2}, \mathrm{NO}_{3}\right)$ is delivered to the

461 reduced water causing a drop in As concentrations (Figure 9A).

462 Although surface recharge provides an oxidant that temporarily decreases As concentrations, it

463 also may promote As reduction and release at depth during anoxic periods. Modest DOC influx

464 from the surface can stimulate enhanced reactivity of buried carbon at depth (Fontaine et al.,

465 2007), and influx of an oxidant such as $\mathrm{O}_{2}$ has been shown to increase the reactivity of in situ

466 carbon compounds via direct (self-priming) oxidation (Aller, 1994) or indirect (Hall and Silver,

467 2013) mechanisms that include production or activation of oxidative hydrolytic enzymes that

468 initiate organic matter decomposition/alteration. Because a seasonal switch to aerobic

469 conditions may make more $\mathrm{C}$ compounds subject to oxidation compared to anaerobic

470 conditions (LaRowe and Van Cappellen, 2011; Keiluweit et al., 2016), seasonal incursions of $\mathrm{O}_{2}$

471 could further oxidize $\mathrm{C}$ compounds that were thermodynamically unavailable under anaerobic

472 conditions and provide a renewed source of oxidized C compounds seasonally. This annually

473 renewed source of relatively oxidized $\mathrm{C}$ compounds would make Fe(III) reduction reactions

474 thermodynamically viable after $\mathrm{O}_{2}$ is consumed. Further, $\mathrm{Fe}$ (II) and $\mathrm{As}(\mathrm{III})$ are oxidized during

475 this period, potentially forming a phase that is more reactive toward microbial reductive

476 dissolution upon transition to anaerobic conditions. The decrease in $\mathrm{Fe}(\mathrm{II})_{(\mathrm{aq})}$ also serves to

477 make the energetics of Fe(III) reduction more viable following the aerobic period. Thus,

478 dissolved oxygen, and possibly nitrate, that leads to a temporary decrease in As concentrations

479 likely also regenerates the reactivity of the in-situ carbon source with $\mathrm{As}(\mathrm{V})-\mathrm{Fe}(\mathrm{III})$ oxides,

480 leading to season shifts in groundwater As concentrations of up to $1000 \mu \mathrm{g} \mathrm{L^{-1 }}$. 


\subsection{Relevance to Other Major River Basins of Asia}

482 Arsenic is mobilized through reductive dissolution of Fe/As oxides throughout Asia, but

483 differences in the source of organic carbon and the reactivity of the Fe/As oxides varies. In the

484 Red River Delta, sediment burial age and reactivity of sedimentary carbon have been used to

485 explain spatial variation in As concentrations (Postma et al., 2012). In the Mekong Delta, the

486 dominant process leading to As contaminated aquifers results from reduction of surficial fine-

487 grained sediments combined with vertical transport of solutes to the aquifer (Polizzotto et al.,

488 2008; Kocar et al., 2008); thus the spatial distribution of As depends on land surface features

489 and hydrology. In the Ganges-Brahmaputra-Meghna delta system, a variety of carbon sources

490 have been proposed to explain As concentrations in the subsurface. A process of surficial As

491 release similar to the Mekong has been posited (Polizzotto et al., 2005) as well as Fe(III)

492 reduction sustained by transport of surface-derived carbon to the subsurface (Harvey et al.,

493 2002; Mailloux et al., 2013) or by detrital organic carbon (Meharg et al., 2006). In contrast, the

494 processes controlling As concentrations in the Jianghan Plain differ from As contaminated

495 aquifers in South and Southeast Asia despite the similarities in sediment origin. Throughout the

496 sediment profile in the Jianghan Plain, arsenic exists as a combination of $\mathrm{H}_{\mathrm{x}} \mathrm{AsO}_{4}{ }^{3-\mathrm{x}}, \mathrm{H}_{\mathrm{x}} \mathrm{AsO}_{3}{ }^{3-\mathrm{x}}$,

497 and arsenic sulfides (Figure 3, Table 3). However, unlike As-contaminated systems in South and

498 Southeast Asia, sediment in the Jianghan Plain is arsenic-enriched in an oxidized layer $\sim 20 \mathrm{~m}$

499 below the surface (Figure 2), and As is readily released from aquifer sediments. Seasonal

500 changes in As concentrations at the field site (Schaefer et al., 2016) are consistent with rapid As

501 release in laboratory incubations (Figure EA-2, EA-3). Sediments with low carbon content would

502 not release significant amounts of As without addition of an exogenous source of reactive 
503 carbon such as inflow of DOC (Harvey et al., 2002; Neumann et al., 2010; Mailloux et al., 2013).

504 However, we have previously shown that at this field area, groundwater recharge results in

505 decreased As concentrations due to aquifer oxidation (Schaefer et al., 2016). In the Jianghan

506 plain, we find that detrital carbon is sufficiently reactive with in-situ Fe(III) minerals to cause

507 reduction and transfer of As from the solid to aqueous phase.

\section{4.4 Potential for Future Arsenic Release}

509 Depth integration of bulk solid phase As concentrations (Figure 2, Table 2) shows that 390-728

$510 \mathrm{~g}$ As per $\mathrm{m}^{2}$ resides in the As-enriched zone alone. This implies that each $\mathrm{m}^{2}$ of the field area

511 containing similar stratigraphy has the potential to contaminate $39-73 \times 10^{6} \mathrm{~L}(39,000-73,000$

$512 \mathrm{~m}^{3}$ ) of water to the $10 \mu \mathrm{g} \mathrm{L} \mathrm{L}^{-1}$ level, or $390-730 \mathrm{~m}^{3}$ of water to $1000 \mu \mathrm{g} \mathrm{L}^{-1}$. Guided by our batch

513 incubations, we estimate that $10-20 \%$ of the sediment-associated As is easily mobilized and

514 thus each square meter with similar stratigraphy has the potential to contaminate $39-73 \mathrm{~m}^{3}$

515 (10\% release) or $78-146 \mathrm{~m}^{3}$ (20\% release) of water to $1000 \mathrm{\mu g} \mathrm{L}^{-1}$. Assuming a vertical column of

516 water beneath this zone and a porosity of 0.4, the As-enriched zone could supply As sufficient

517 to contaminate the entire aquifer to $1000 \mu \mathrm{g} \mathrm{L}-1$ to a depth of $100-360 \mathrm{~m}$ (using various

518 assumptions and calculations of depth integration and $10-20 \%$ release). Finally, using

519 conservative estimates ( $390 \mathrm{~g} \mathrm{As} \mathrm{m}^{-2}, 10 \%$ of As available for release, As-enriched zone as the

520 sole source of As) the As-enriched zone needs to extend under only $5 \%$ of the land area to

521 explain As concentrations throughout the aquifer in July 2013, the month of peak As

522 concentrations observed at the site (Duan et al., 2015; Schaefer et al., 2016). 


\section{5. CONCLUSIONS}

525 Annual variations in $\mathrm{As}, \mathrm{Fe}(\mathrm{II})$, and $\mathrm{S}^{2-}$ concentrations in the Jianghan Plain arise from seasonally

526 shifting surface and groundwater flow gradients and an associated oscillation of reductive and

527 oxidative processes (Schaefer et al., 2016). Arsenic-enriched sediment at $\sim 20 \mathrm{~m}$ depth provides

528 a source of As to the aquifer. Batch sediment incubations showed that the arsenic in this zone

529 undergoes reductive dissolution, especially when stimulated by glucose addition (Figure 7),

530 although an exogenous carbon source was not necessary for substantial As release. The

531 oxidative formation and reductive dissolution of Fe(III)-oxides under seasonal redox changes

532 explains the observed seasonal variability in As concentrations at the field area. These results

533 support deep sediment reductive release of arsenic. Our observations suggest that within the

534 Jianghan plain sediments, under current conditions, organic carbon in the sediments is capable

535 of promoting As release. However, we cannot discount the potential of surface derived DOC as

536 an additional driver of As mobilization. Seasonal changes in groundwater flow likely drive redox

537 cycling; the specific role of hydrological change in supplying or modifying organic carbon

538 remains unknown but likely promotes the reactivity of both organic matter and As-bearing

539 Fe(III) oxides.

540 From the Jianghan plain, we surmise that As concentrations are altered by human activities

541 changing subsurface hydrology and chemistry; land use changes that may alter arsenic include

542 pond excavation (Neumann et al., 2010), groundwater extraction, and infiltration of organic

543 compounds (Ziegler et al., 2015). Likewise, continued monitoring of As concentrations used for

544 drinking and irrigation is necessary across Asia as we continue to understand the complex

545 mechanisms leading to As contamination in Asian groundwater. 


\section{ACKNOWLEDGEMENTS}

547 This work was funded by the National Natural Science Foundation of China (No. 41521001 and

548 No. 41120124003) and the Chinese Ministry of Science and Technology (2014DFA20720).

549 Portions of this work were also supported by the US National Science Foundation (grant

550 number EAR-0952019), a US National Science Foundation Graduate Research Fellowship

551 Program Grant No. DGE-114747 awarded to M.V. Schaefer, and the EVP program of Stanford's

552 Woods Institute. We would like to thank Jay Dynes, Juan Salvador Lezama Pacheco, Marco

553 Keiluweit, and Tom Regier for help with measurements and interpretation of XAS data and

554 Yanhua Duan, Guangchao Li, Jason Stuckey, Doug Turner, Samantha Ying, and many staff and

555 students at China University of Geoscience - Wuhan for help in the field and laboratory.

556 Portions of this research were carried out at the Stanford Synchrotron Radiation Lightsource, a

557 Directorate of SLAC National Accelerator Laboratory and an Office of Science User Facility

558 operated for the U.S. Department of Energy Office of Science by Stanford University. Research

559 described in this paper was performed at the Canadian Light Source, which is supported by the

560 Canada Foundation for Innovation, Natural Sciences and Engineering Research Council of

561 Canada, the University of Saskatchewan, the Government of Saskatchewan, Western Economic

562 Diversification Canada, the National Research Council Canada, and the Canadian Institutes of

563 Health Research. 


\section{RefERENCES}

Aller R. C. (1994) Bioturbation and remineralization of sedimentary organic matter: effects of redox oscillation. Chem. Geol. 114, 331-345.

Ayotte J. D., Belaval M., Olson S. A., Burow K. R., Flanagan S. M., Hinkle S. R. and Lindsey B. D. (2015) Factors affecting temporal variability of arsenic in groundwater used for drinking water supply in the United States. Sci. Total Environ. 505, 1370-1379.

Benner S. G., Polizzotto M. L., Kocar B. D., Ganguly S., Phan K., Ouch K., Sampson M. and Fendorf S. (2008) Groundwater flow in an arsenic-contaminated aquifer, Mekong Delta, Cambodia. Appl. Geochem. 23, 3072-3087.

Blaauw C., Stroink G. and Leiper W. (1980) Mössbauer analysis of talc and chlorite. J Phys Colloq. 41, C1-411-C1-412.

Cheng Z., van Geen A., Seddique A. A. and Ahmed K. M. (2005) Limited Temporal Variability of Arsenic Concentrations in 20 Wells Monitored for 3 Years in Araihazar, Bangladesh. Environ. Sci. Technol. 39, 4759-4766.

Das N. K., Sengupta S. R. and others (2008) Arsenicosis: diagnosis and treatment. Indian J. Dermatol. Venereol. Leprol. 74, 571.

Dhar R. K., Zheng Y., Saltikov C. W., Radloff K. A., Mailloux B. J., Ahmed K. M. and van Geen A. (2011) Microbes Enhance Mobility of Arsenic in Pleistocene Aquifer Sand from Bangladesh. Environ. Sci. Technol. 45, 2648-2654.

Dixit S. and Hering J. G. (2003) Comparison of arsenic(V) and arsenic(III) sorption onto iron oxide minerals: Implications for arsenic mobility. Environ. Sci. Technol. 37, 4182-4189.

Duan Y., Gan Y., Wang Y., Deng Y., Guo X. and Dong C. (2015) Temporal variation of groundwater level and arsenic concentration at Jianghan Plain, central China. $J$. Geochem. Explor. 149, 106-119.

Fendorf S., Eick M. J., Grossl P. and Sparks D. L. (1997) Arsenate and chromate retention mechanisms on goethite. 1. Surface structure. Environ. Sci. Technol. 31, 315-320.

Fendorf S., Michael H. A. and van Geen A. (2010) Spatial and Temporal Variations of Groundwater Arsenic in South and Southeast Asia. Science 328, 1123-1127.

Fontaine S., Barot S., Barré P., Bdioui N., Mary B. and Rumpel C. (2007) Stability of organic carbon in deep soil layers controlled by fresh carbon supply. Nature 450, 277-280.

Gan Y., Wang Y., Duan Y., Deng Y., Guo X. and Ding X. (2014) Hydrogeochemistry and arsenic contamination of groundwater in the Jianghan Plain, central China. J. Geochem. Explor. 138, 81-93.

van Geen A., Zheng Y., Versteeg R., Stute M., Horneman A., Dhar R., Steckler M., Gelman A., Small C., Ahsan H., Graziano J. H., Hussain I. and Ahmed K. M. (2003) Spatial 
variability of arsenic in 6000 tube wells in a $25 \mathrm{~km} 2$ area of Bangladesh. Water Resour. Res. 39, 1140.

Gehin A., Greneche J. M., Tournassat C., Brendle J., Rancourt D. G. and Charlet L. (2007) Reversible surface-sorption-induced electron-transfer oxidation of Fe(II) at reactive sites on a synthetic clay mineral. Geochim. Cosmochim. Acta 71, 863-876.

Hall S. J. and Silver W. L. (2013) Iron oxidation stimulates organic matter decomposition in humid tropical forest soils. Glob. Change Biol. 19, 2804-2813.

Harvey C. F., Ashfaque K. N., Yu W., Badruzzaman A. B. M., Ali M. A., Oates P. M., Michael H. A., Neumann R. B., Beckie R., Islam S. and Ahmed M. F. (2006) Groundwater dynamics and arsenic contamination in Bangladesh. Chem. Geol. 228, 112-136.

Harvey C. F., Swartz C. H., Badruzzaman A. B. M., Keon-Blute N., Yu W., Ali M. A., Jay J., Beckie R., Niedan V., Brabander D., Oates P. M., Ashfaque K. N., Islam S., Hemond H. F. and Ahmed M. F. (2002) Arsenic mobility and groundwater extraction in Bangladesh. Science 298, 1602-1606.

Hitchcock A. P., Hitchcock P., Jacobsen C., Zimba C., Loo B., Rotenberg E., Denlinger J. and Kneedler R. (2012) aXis 2000-Analysis of X-ray Images and Spectra. McMaster Univ. Hamilt.

Islam F. S., Gault A. G., Boothman C., Polya D. A., Charnock J. M., Chatterjee D. and Lloyd J. R. (2004) Role of metal-reducing bacteria in arsenic release from Bengal delta sediments. Nature 430, 68-71.

Keiluweit M., Nico P. S., Kleber M. and Fendorf S. (2016) Are oxygen limitations under recognized regulators of organic carbon turnover in upland soils? Biogeochemistry, 1-15.

Kleber M., Nico P. S., Plante A., Filley T., Kramer M., Swanston C. and Sollins P. (2011) Old and stable soil organic matter is not necessarily chemically recalcitrant: implications for modeling concepts and temperature sensitivity. Glob. Change Biol. 17, 1097-1107.

Kocar B. D., Herbel M. J., Tufano K. J. and Fendorf S. (2006) Contrasting effects of dissimilatory iron(III) and $\operatorname{arsenic}(\mathrm{V})$ reduction on arsenic retention and transport. Environ. Sci. Technol. 40, 6715-6721.

Kocar B. D., Polizzotto M. L., Benner S. G., Ying S. C., Ung M., Ouch K., Samreth S., Suy B., Phan K., Sampson M. and Fendorf S. (2008) Integrated biogeochemical and hydrologic processes driving arsenic release from shallow sediments to groundwaters of the Mekong delta. Appl. Geochem. 23, 3059-3071.

Larese-Casanova P., Cwiertny D. M. and Scherer M. M. (2010) Nanogoethite Formation from Oxidation of Fe(II) Sorbed on Aluminum Oxide: Implications for Contaminant Reduction. Environ. Sci. Technol. 44, 3765-3771. 
635

636

637

638

639

640

641

642

643

644

645

646

647

648

649

650

651

652

653

654

655

656

657

658

659

660

661

662

663

664

665

666

667

668

LaRowe D. E. and Van Cappellen P. (2011) Degradation of natural organic matter: A thermodynamic analysis. Geochim. Cosmochim. Acta 75, 2030-2042.

Lawson M., Polya D. A., Boyce A. J., Bryant C. and Ballentine C. J. (2016) Tracing organic matter composition and distribution and its role on arsenic release in shallow Cambodian groundwaters. Geochim. Cosmochim. Acta 178, 160-177.

Lowers H. A., Breit G. N., Foster A. L., Whitney J., Yount J., Uddin M. N. and Muneem A. A. (2007) Arsenic incorporation into authigenic pyrite, Bengal Basin sediment, Bangladesh. Geochim. Cosmochim. Acta 71, 2699-2717.

Mailloux B. J., Trembath-Reichert E., Cheung J., Watson M., Stute M., Freyer G. A., Ferguson A. S., Ahmed K. M., Alam M. J., Buchholz B. A., Thomas J., Layton A. C., Zheng Y., Bostick B. C. and Geen A. van (2013) Advection of surface-derived organic carbon fuels microbial reduction in Bangladesh groundwater. Proc. Natl. Acad. Sci. 110, 5331-5335.

McArthur J. M., Banerjee D. M., Hudson-Edwards K. A., Mishra R., Purohit R., Ravenscroft P., Cronin A., Howarth R. J., Chatterjee A., Talukder T., Lowry D., Houghton S. and Chadha D. K. (2004) Natural organic matter in sedimentary basins and its relation to arsenic in anoxic ground water: the example of West Bengal and its worldwide implications. Appl. Geochem. 19, 1255-1293.

McArthur J. M., Banerjee D. M., Sengupta S., Ravenscroft P., Klump S., Sarkar A., Disch B. and Kipfer R. (2010) Migration of As, and 3H/3He ages, in groundwater from West Bengal: Implications for monitoring. Water Res. 44, 4171-4185.

Meharg A. A., Scrimgeour C., Hossain S. A., Fuller K., Cruickshank K., Williams P. N. and Kinniburgh D. G. (2006) Codeposition of Organic Carbon and Arsenic in Bengal Delta Aquifers. Environ. Sci. Technol. 40, 4928-4935.

Michael H. A. (2013) An Arsenic Forecast for China. Science 341, 852-853.

Murad E. and Cashion J. (2004) Mossbauer Spectroscopy of Environmental Materials and their Industrial Utilization., Kluwer Academic Publishers.

Naujokas M. F., Anderson B., Ahsan H., Aposhian H. V., Graziano J. H., Thompson C. and Suk W. A. (2013) The Broad Scope of Health Effects from Chronic Arsenic Exposure: Update on a Worldwide Public Health Problem. Environ. Health Perspect. 121, 295-302.

Neumann R. B., Ashfaque K. N., Badruzzaman A. B. M., Ali M. A., Shoemaker J. K. and Harvey C. F. (2010) Anthropogenic influences on groundwater arsenic concentrations in Bangladesh. Nat. Geosci. 3, 46-52.

Nickson R., McArthur J., Burgess W., Ahmed K. M., Ravenscroft P. and Rahman M. (1998) Arsenic poisoning of Bangladesh groundwater. Nature 395, 338-338. 
669

670

671

672

673

674

675

676

677

678

679

680

681

682

683

684

685

686

687

688

689

690

691

692

693

694

695

696

697

698

699

700

701

702

703

704

705

Nickson R. T., McArthur J. M., Ravenscroft P., Burgess W. G. and Ahmed K. M. (2000) Mechanism of arsenic release to groundwater, Bangladesh and West Bengal. Appl. Geochem. 15, 403-413.

Pedersen H. D., Postma D. and Jakobsen R. (2006) Release of arsenic associated with the reduction and transformation of iron oxides. Geochim. Cosmochim. Acta 70, 4116-4129.

Polizzotto M. L., Harvey C. F., Sutton S. R. and Fendorf S. (2005) Processes conducive to the release and transport of arsenic into aquifers of Bangladesh. Proc. Natl. Acad. Sci. U. S. A. 102, 18819-18823.

Polizzotto M. L., Kocar B. D., Benner S. G., Sampson M. and Fendorf S. (2008) Near-surface wetland sediments as a source of arsenic release to ground water in Asia. Nature 454, 505-U5.

Postma D., Larsen F., Thai N. T., Trang P. T. K., Jakobsen R., Nhan P. Q., Long T. V., Viet P. H. and Murray A. S. (2012) Groundwater arsenic concentrations in Vietnam controlled by sediment age. Nat. Geosci. 5, 656-661.

Rancourt D. G. and Ping J. Y. (1991) Voight-based methods for arbitrary-shape static hyperfine parameter distributions in Mössbauer spectroscopy. Nucl. Instrum. Methods Phys. Res. B58, 85-97.

Ravel B. and Newville M. (2005) ATHENA, ARTEMIS, HEPHAESTUS: data analysis for Xray absorption spectroscopy using IFEFFIT. J. Synchrotron Radiat. 12, 537-541.

Richards L. A., Sültenfuls s J., Magnone D., Boyce A., Sovann C., Casanueva-Marenco M. J., Ballentine C. J., van Dongen B. E. and Polya D. A. (2016) Age and provenance of groundwater in a shallow arsenic-affected aquifer in the lower Mekong Basin, Kandal Province, Cambodia. In Arsenic Research and Global Sustainability: Proceedings of the Sixth International Congress on Arsenic in the Environment (As2016), June 19-23, 2016, Stockholm, Sweden CRC Press. p. 74. Available at: https://books.google.com/books?hl=en\&lr=\&id=XwBPDAAAQBAJ\&oi=fnd\&pg=PA74 \&ots=Nf1qE1RnUT\&sig=1RhAhMPe0x0XVKpFgwT-D1QeLtM [Accessed July 22, 2016].

Rodríguez-Lado L., Sun G., Berg M., Zhang Q., Xue H., Zheng Q. and Johnson C. A. (2013) Groundwater Arsenic Contamination Throughout China. Science 341, 866-868.

Schaefer M. V., Gorski C. A. and Scherer M. M. (2011) Spectroscopic Evidence for Interfacial Fe(II)-Fe(III) Electron Transfer in a Clay Mineral. Environ. Sci. Technol. 45, 540-545.

Schaefer M. V., Ying S. C., Benner S. G., Duan Y., Wang Y. and Fendorf S. (2016) Aquifer Arsenic Cycling Induced by Seasonal Hydrologic Changes within the Yangtze River Basin. Environ. Sci. Technol. 50, 3521-3529.

Schumacher M., Christl I., Scheinost A. C., Jacobsen C. and Kretzschmar R. (2005) Chemical Heterogeneity of Organic Soil Colloids Investigated by Scanning Transmission X-ray 
706

707

708

709

710

711

712

713

714

715

716

717

718

719

720

721

722

723

724

725

726

727

728

729

730

731

732

733

734

735

736

737

738

739

740

Microscopy and C-1s NEXAFS Microspectroscopy. Environ. Sci. Technol. 39, 90949100.

Smedley P. L. and Kinniburgh D. G. (2002) A review of the source, behaviour and distribution of arsenic in natural waters. Appl. Geochem. 17, 517-568.

Stahl M. O., Tarek M. H., Yeo D. C. J., Badruzzaman A. B. M. and Harvey C. F. (2014) Crab burrows as conduits for groundwater-surface water exchange in Bangladesh. Geophys. Res. Lett. 41, 2014GL061626.

Steinmaus C., Moore L., Hopenhayn-Rich C., Biggs M. L. and Smith A. H. (2000) Arsenic in Drinking Water and Bladder Cancer: Environmental Carcinogenesis. Cancer Invest. 18, 174-182.

Stuckey J. W., Schaefer M. V., Kocar B. D., Benner S. G. and Fendorf S. (2016) Arsenic release metabolically limited to permanently water-saturated soil in Mekong Delta. Nat. Geosci. 9, 70-76.

Tamura H., Goto K., Yotsuyanagi T. and Nagayama M. (1974) Spectrophotometric determination of iron (II) with 1, 10-phenanthroline in the presence of large amounts of iron (III). Talanta 21, 314-318.

Tufano K. J. and Fendorf S. (2008) Confounding impacts of iron reduction on arsenic retention. Environ. Sci. Technol. 42, 4777-4783.

Tufano K. J., Reyes C., Saltikov C. W. and Fendorf S. (2008) Reductive Processes Controlling Arsenic Retention: Revealing the Relative Importance of Iron and Arsenic Reduction. Environ. Sci. Technol. 42, 8283-8289.

Wasserman G. A., Liu X. H., Parvez F., Ahsan H., Factor-Litvak P., van Geen A., Slavkovich V., Lolacono N. J., Cheng Z. Q., Hussain L., Momotaj H. and Graziano J. H. (2004) Water arsenic exposure and children's intellectual function in Araihazar, Bangladesh. Environ. Health Perspect. 112, 1329-1333.

Wasserman G. A., Liu X., Parvez F., Ahsan H., Factor-Litvak P., Kline J., Geen A. van, Slavkovich V., Lolacono N. J., Levy D., Cheng Z. and Graziano J. H. (2007) Water Arsenic Exposure and Intellectual Function in 6-Year-Old Children in Araihazar, Bangladesh. Environ. Health Perspect. 115, 285-289.

Waychunas G. A., Rea B. A., Fuller C. C. and Davis J. A. (1993) Surface chemistry of ferrihydrite: Part 1. EXAFS studies of the geometry of coprecipitated and adsorbed arsenate. Geochim. Cosmochim. Acta 57, 2251-2269.

Winkel L. H. E., Trang P. T. K., Lan V. M., Stengel C., Amini M., Ha N. T., Viet P. H. and Berg M. (2011) Arsenic pollution of groundwater in Vietnam exacerbated by deep aquifer exploitation for more than a century. Proc. Natl. Acad. Sci. 108, 1246-1251. 
741 Zhang Y., Li C., Wang Q., Chen L., Ma Y. and Kang C. (2008) Magnetism parameters 742 characteristics of drilling deposits in Jianghan Plain and indication for forming of the $743 \quad$ Yangtze River Three Gorges. Chin. Sci. Bull. 53, 584-590.

744 Ziegler B. A., McGuire J. T. and Cozzarelli I. M. (2015) Rates of As and Trace-Element $745 \quad$ Mobilization Caused by Fe Reduction in Mixed BTEX-Ethanol Experimental Plumes. $746 \quad$ Environ. Sci. Technol. 49, 13179-13189. 


\section{TABLES}

Table 1. Groundwater Chemistry for the Jianghan Plain Site from May 2012 to December 2014

\begin{tabular}{lccccc} 
Parameter & min & $\max$ & mean & median & $\mathrm{n}$ \\
\hline Arsenic $\left(\mu \mathrm{g} \mathrm{L}^{-1}\right)$ & b.d. & 1205 & 65 & 35 & 1240 \\
Sulfide $\left(\mu \mathrm{g} \mathrm{L}^{-1}\right)$ & b.d. & 476 & 39 & 15 & 1105 \\
Iron $\left(\mathrm{mg} \mathrm{L}^{-1}\right)$ & b.d. & 39.8 & 5.1 & 4.2 & 1198 \\
Manganese $\left(\mathrm{mg} \mathrm{L}^{-1}\right)$ & b.d. & 9.58 & 1.3 & 0.68 & 1185 \\
Conductivity $\left(\mu \mathrm{S} \mathrm{cm}^{-1}\right)$ & 233 & 1585 & 922 & 874 & 1202 \\
Eh $(\mathrm{mV})$ & 9.6 & 471 & 130 & 119 & 1199 \\
pH & 5.96 & 7.89 & 7.12 & 7.13 & 1202 \\
Temperature $\left({ }^{\circ} \mathrm{C}\right)$ & 12.9 & 26.4 & 19.3 & 19.3 & 1202 \\
${ }^{1}$ below detection & & & & &
\end{tabular}


Table 2. Bulk Elemental Concentrations of Sediment Samples

\begin{tabular}{|c|c|c|c|c|c|c|c|c|c|}
\hline Depth & $\mathrm{C}$ & $\mathrm{Al}$ & Si & $P$ & $S$ & $\mathrm{Ti}$ & $\mathrm{Mn}$ & $\mathrm{Fe}$ & As \\
\hline $\mathrm{m}$ & $\mathrm{g} / \mathrm{kg}$ & $\mathrm{g} / \mathrm{kg}$ & $\mathrm{g} / \mathrm{kg}$ & $\mathrm{mg} / \mathrm{kg}$ & $\mathrm{mg} / \mathrm{kg}$ & $\mathrm{g} / \mathrm{kg}$ & $\mathrm{mg} / \mathrm{kg}$ & $\mathrm{g} / \mathrm{kg}$ & $\mathrm{mg} / \mathrm{kg}$ \\
\hline 1.5 & 7.9 & 117 & 294 & 610 & 96 & 4.8 & 931 & 49.2 & 12.2 \\
\hline 2.5 & 7.9 & 132 & 274 & 580 & 121 & 4.6 & 855 & 61.3 & 19.2 \\
\hline 3.7 & 15.9 & 96 & 245 & 433 & 315 & 5.0 & 539 & 52.7 & 11.7 \\
\hline 4.7 & 14.4 & 114 & 243 & 367 & 1055 & 4.8 & 501 & 50.1 & 17.2 \\
\hline 5.9 & 13.6 & 105 & 315 & 557 & 379 & 4.4 & 639 & 38.1 & 6.4 \\
\hline 7.1 & 11.3 & 93 & 261 & 582 & 410 & 5.1 & 780 & 46.7 & 11.3 \\
\hline 8.3 & 18.2 & 99 & 246 & 408 & 2545 & 4.8 & 408 & 53.9 & 8.4 \\
\hline 9.5 & 27.1 & 83 & 232 & 580 & 464 & 5.3 & 1083 & 47.3 & 3.9 \\
\hline 10.3 & 19.9 & 69 & 248 & 476 & 871 & 4.1 & 636 & 33.9 & 1.8 \\
\hline 11.9 & 18.1 & 62 & 253 & 447 & 890 & 3.7 & 523 & 28.2 & 0.0 \\
\hline 12 & 18.4 & 72 & 247 & 469 & 1130 & 4.2 & 602 & 33.8 & 2.2 \\
\hline 14.1 & 13.7 & 71 & 272 & 506 & 595 & 4.4 & 524 & 30.3 & 2.8 \\
\hline 14.3 & 6.6 & 75 & 255 & 503 & 495 & 4.7 & 719 & 38.7 & 1.5 \\
\hline 15.2 & 1.6 & 103 & 324 & 392 & 113 & 4.2 & 331 & 40.1 & 1.4 \\
\hline 16.5 & 19.6 & 98 & 249 & 463 & 1665 & 4.5 & 514 & 51.4 & 9.9 \\
\hline 17.9 & 2.7 & 96 & 259 & 919 & 12 & 5.1 & 870 & 55.4 & 20.0 \\
\hline 18.7 & 1.4 & 107 & 313 & 812 & 20 & 4.4 & 690 & 43.1 & 88.2 \\
\hline 20.1 & 1.6 & 86 & 316 & 1139 & 21 & 4.9 & 616 & 35.6 & 107.5 \\
\hline 21.9 & 0.4 & 81 & 353 & 923 & 52 & 3.9 & 470 & 26.5 & 4.4 \\
\hline 23.3 & 1.2 & 99 & 318 & 1239 & 31 & 4.4 & 909 & 38.0 & 24.2 \\
\hline 25.1 & 0.5 & 79 & 352 & 1077 & 46 & 4.0 & 510 & 27.4 & 6.0 \\
\hline 26.8 & 0.6 & 91 & 345 & 746 & 165 & 3.6 & 321 & 25.4 & 0.0 \\
\hline 28.9 & 2.2 & 81 & 275 & 530 & 255 & 3.8 & 441 & 27.4 & 3.3 \\
\hline 30.1 & 6.7 & 67 & 266 & 5555 & 134 & 4.1 & 441 & 27.6 & 0.0 \\
\hline 30.9 & 22.6 & 60 & 235 & 253 & 2034 & 3.1 & 504 & 31.1 & 25.6 \\
\hline 31.6 & 3.9 & 57 & 256 & 499 & 567 & 3.7 & 415 & 23.1 & 0.0 \\
\hline 35.2 & 5.8 & 85 & 258 & 533 & 1111 & 4.2 & 701 & 37.4 & 7.2 \\
\hline 37 & 2.5 & 117 & 311 & 635 & 33 & 4.9 & 220 & 53.4 & 9.9 \\
\hline 37.9 & 12.1 & 70 & 239 & 399 & 540 & 3.6 & 603 & 29.1 & 1.0 \\
\hline 41.2 & 5.6 & 39 & 259 & 267 & 2313 & 1.7 & 272 & 9.5 & 0.7 \\
\hline 42.3 & 16.6 & 105 & 290 & 689 & 306 & 4.6 & 881 & 47.5 & 11.1 \\
\hline 43.5 & 17.9 & 110 & 279 & 731 & 281 & 4.4 & 1064 & 54.1 & 15.5 \\
\hline 44.7 & 20.3 & 109 & 280 & 606 & 301 & 4.5 & 948 & 49.1 & 13.8 \\
\hline 48.5 & 9.7 & 44 & 253 & 779 & 566 & 1.8 & 1022 & 17.6 & 5.5 \\
\hline 50.3 & 16.7 & 60 & 240 & 383 & 508 & 3.4 & 484 & 27.2 & 1.4 \\
\hline 51.4 & 6.2 & 48 & 286 & 361 & 849 & 2.2 & 478 & 16.3 & 3.7 \\
\hline
\end{tabular}


Table 3. Arsenic Speciation Determined by As K-edge XANES Spectroscopy.

Native Sediment

\begin{tabular}{ccccccccccc}
$\begin{array}{c}\text { Depth } \\
(\mathrm{m})\end{array}$ & $\begin{array}{c}\text { Arsenian } \\
\text { Pyrite }\end{array}$ & $\mathrm{H}_{3} \mathrm{AsO}_{3}{ }^{3-}$ & $\mathrm{H}_{3} \mathrm{AsO}_{4}{ }^{3-}$ & $\begin{array}{c}\text { Arsenian } \\
\text { Pyrite }\end{array}$ & $\mathrm{H}_{3} \mathrm{AsO}_{3}{ }^{3-}$ & $\mathrm{H}_{3} \mathrm{AsO}_{4}{ }^{3-}$ & $\begin{array}{c}\Delta \text { Arsenian } \\
\text { Pyrite }\end{array}$ & $\Delta \mathrm{H}_{3} \mathrm{AsO}_{3}{ }^{3-}$ & $\Delta \mathrm{H}_{3} \mathrm{AsO}_{4}{ }^{3-}$ \\
\hline \hline 1.5 & 0.00 & 0.15 & 0.85 & 0.04 & 0.61 & 0.35 & +0.04 & +0.46 & -0.50 \\
2.5 & 0.03 & 0.60 & 0.37 & n.d. & n.d. & n.d. & n.d. & n.d. & n.d. \\
7.1 & 0.23 & 0.51 & 0.25 & 0.35 & 0.56 & 0.09 & +0.12 & +0.05 & -0.17 \\
17.9 & 0.00 & 0.66 & 0.34 & 0.00 & 0.77 & 0.23 & +0.00 & +0.11 & -0.11 \\
18.7 & 0.00 & 0.18 & 0.82 & 0.00 & 0.19 & 0.81 & +0.00 & +0.02 & -0.02 \\
20.1 & 0.00 & 0.47 & 0.53 & 0.00 & 0.78 & 0.22 & +0.00 & +0.32 & -0.32 \\
23.3 & 0.00 & 0.80 & 0.20 & 0.00 & 0.85 & 0.15 & +0.00 & +0.05 & -0.05 \\
30.9 & 0.86 & 0.09 & 0.06 & 0.90 & 0.10 & 0.00 & +0.04 & +0.01 & -0.06 \\
43.5 & 0.24 & 0.73 & 0.03 & 0.30 & 0.70 & 0.00 & +0.06 & -0.04 & -0.03
\end{tabular}




\section{FIGURES}

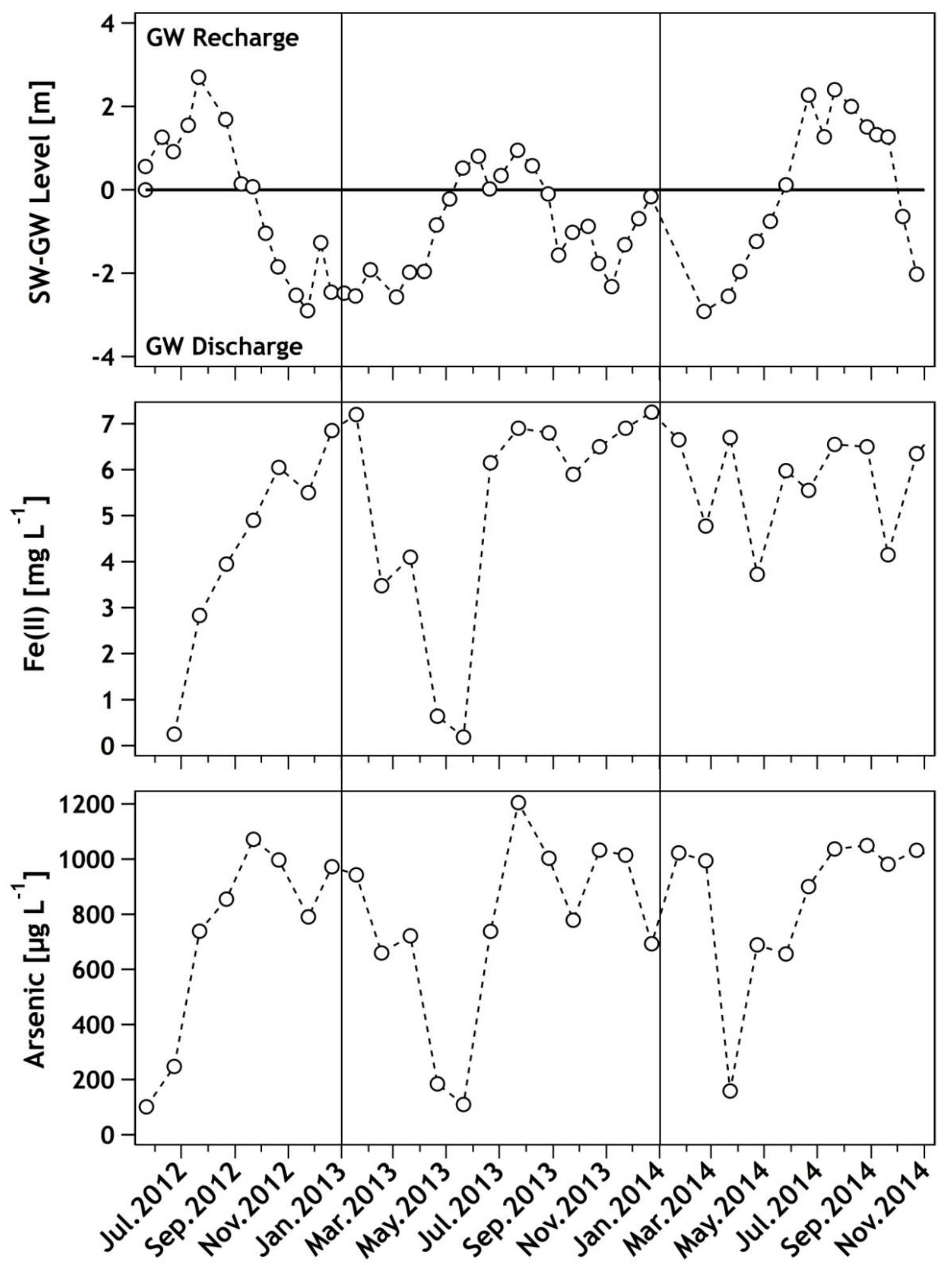

Figure 1. Difference in surface water and groundwater level (SW-GW), and aqueous concentrations of Fe(II) and arsenic, from June 2012-November 2014. Data are from $25 \mathrm{~m}$ at the site of sediment collection. 


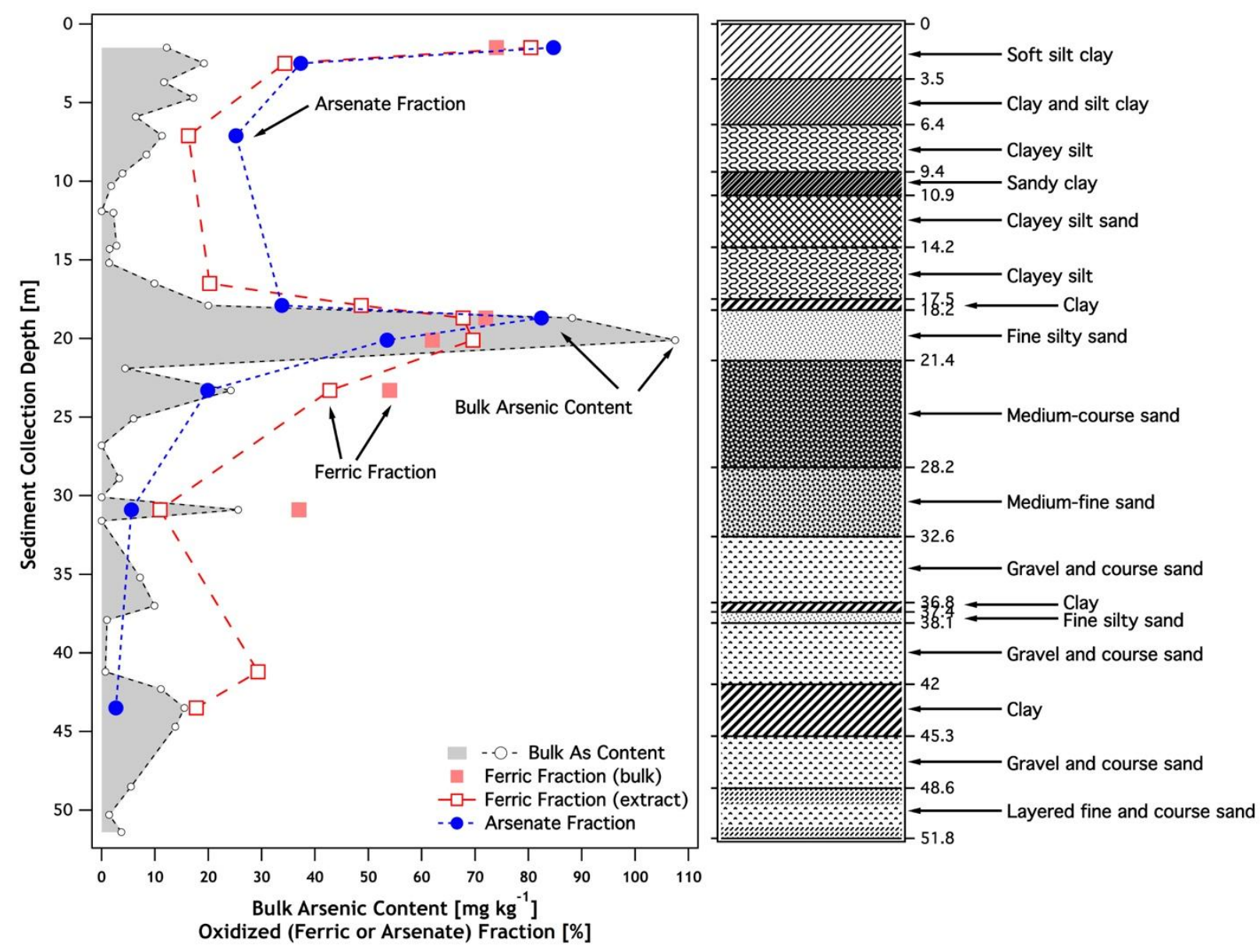

Figure 2. Sediment characterization at borehole SY03. Bulk As content (small circles and grey fill) and arsenate fraction (filled blue circles), bulk ferric fraction determined by Mössbauer spectroscopy (filled red squares), and extractable ferric fraction (open red squares) are plotted as a function of sediment collection depth. Bulk As concentrations were measured by X-ray fluorescence (XRF). Ferric-iron fractions were determined from speciation of $2 \mathrm{M} \mathrm{HCl}$ extracts and represent the Fe(III) fraction of the extracted Fe, not the bulk Fe oxidation state. Arsenate speciation was determined by linear combination fits of bulk As K-edge XANES spectra (complete XANES spectral fits are provided in Figure 2). Sediment texture is shown on the right for reference. 


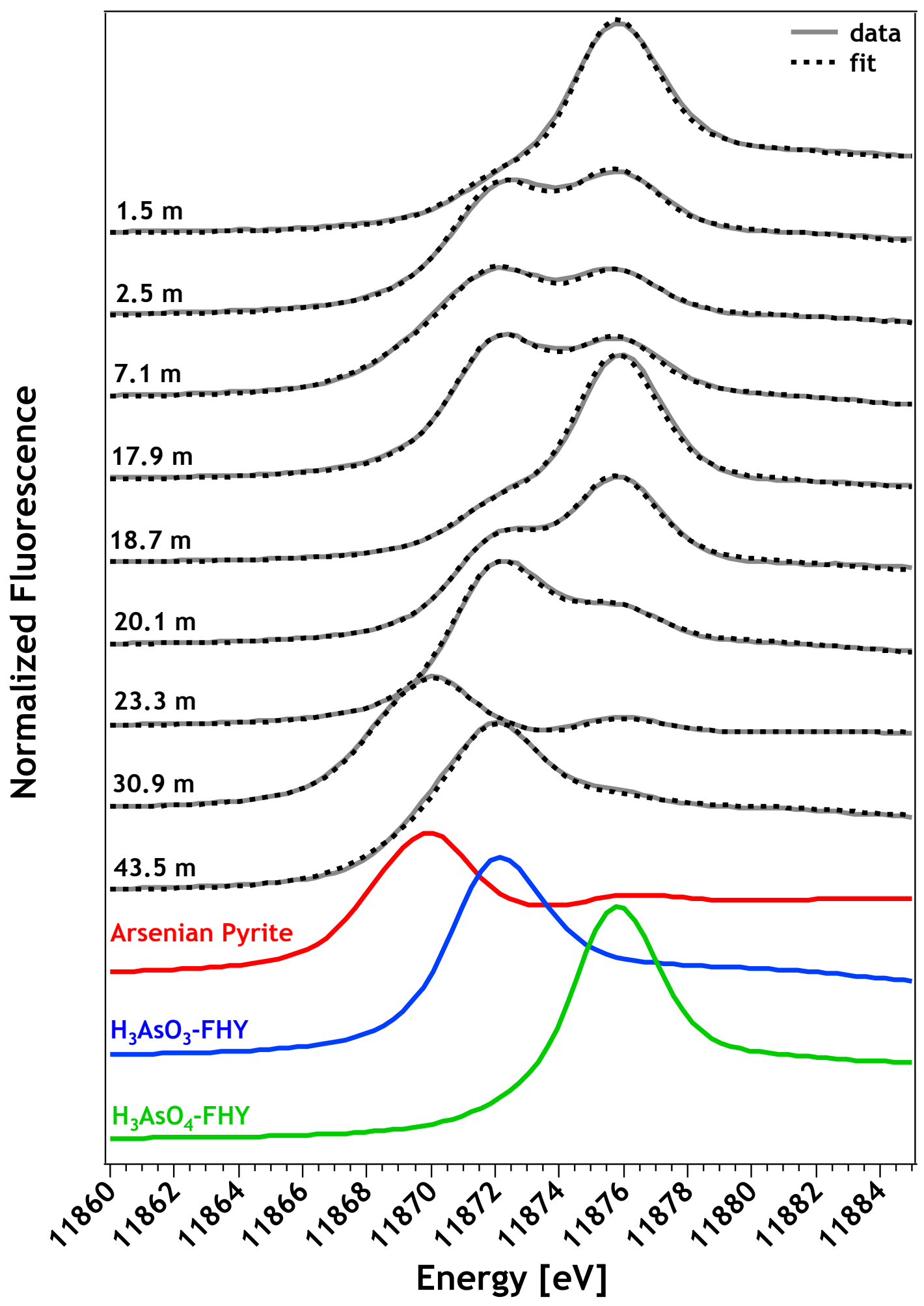

Figure 3. Arsenic K-edge XANES spectra of sediment from borehole SY03. The solid grey line shows normalized absorbance of an average of 3 to 8 spectra. The dotted black line is the best fit determined by linear combination fitting using the three standards shown. 


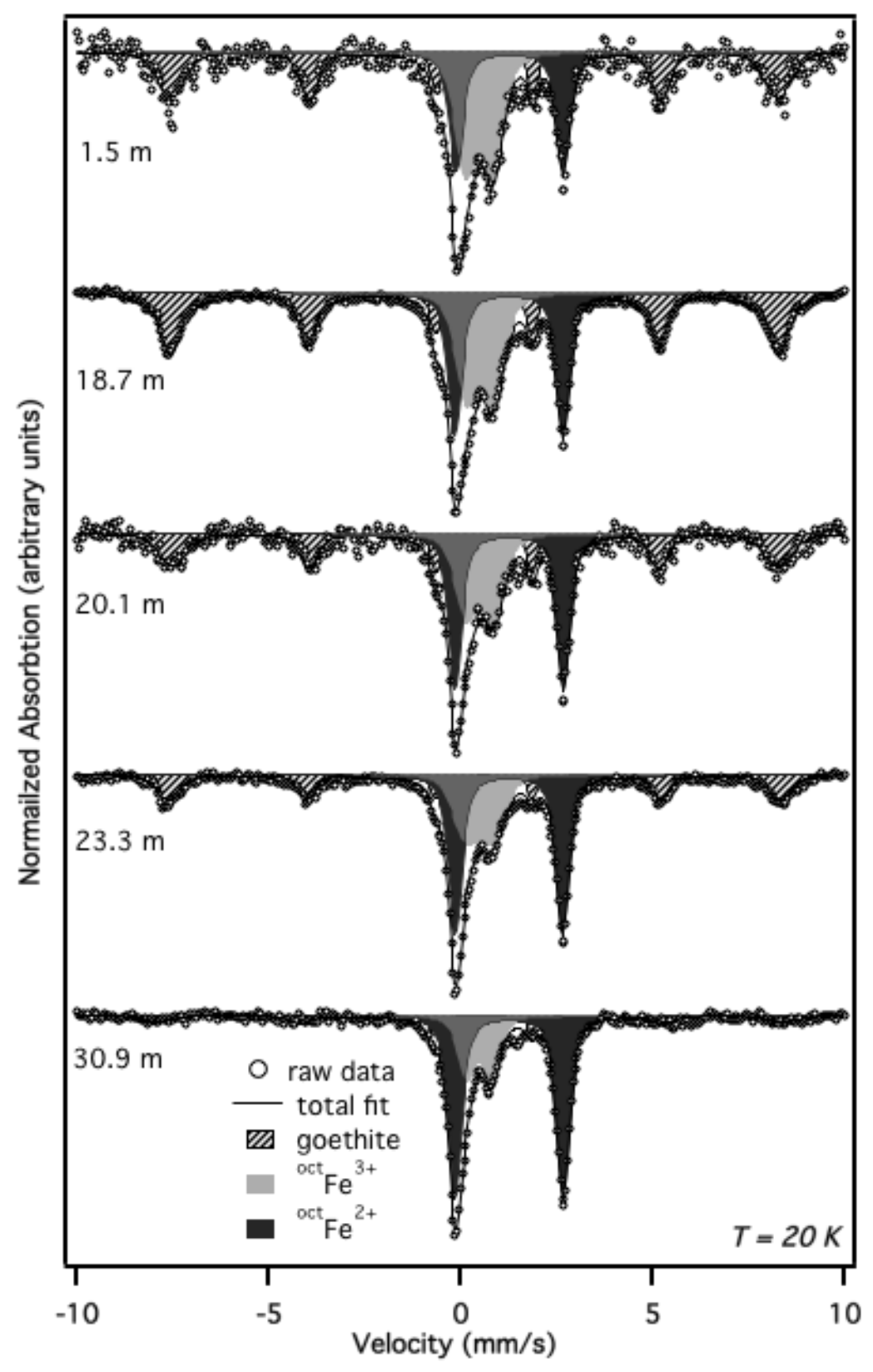

Figure 4. Mössbauer spectra of sediment samples recovered at borehole SY03. All spectra were collected at a temperature of $20 \mathrm{~K}$. Each spectrum was fit as a combination of three Fe phases: an octahedral Fe(II) doublet (solid black), an octahedral Fe(III) doublet that did not magnetically order at $20 \mathrm{~K}$ (solid grey), and a goethite sextet that magnetically ordered at $20 \mathrm{~K}$. The solid line shows the overall fit. While the sextet parameters are indicative of goethite, our interpretation is limited to classifying this phase as a Fe(III) oxide. Mössbauer spectral fit parameters and the relative abundance of each phase are provided in Table SI-1. 


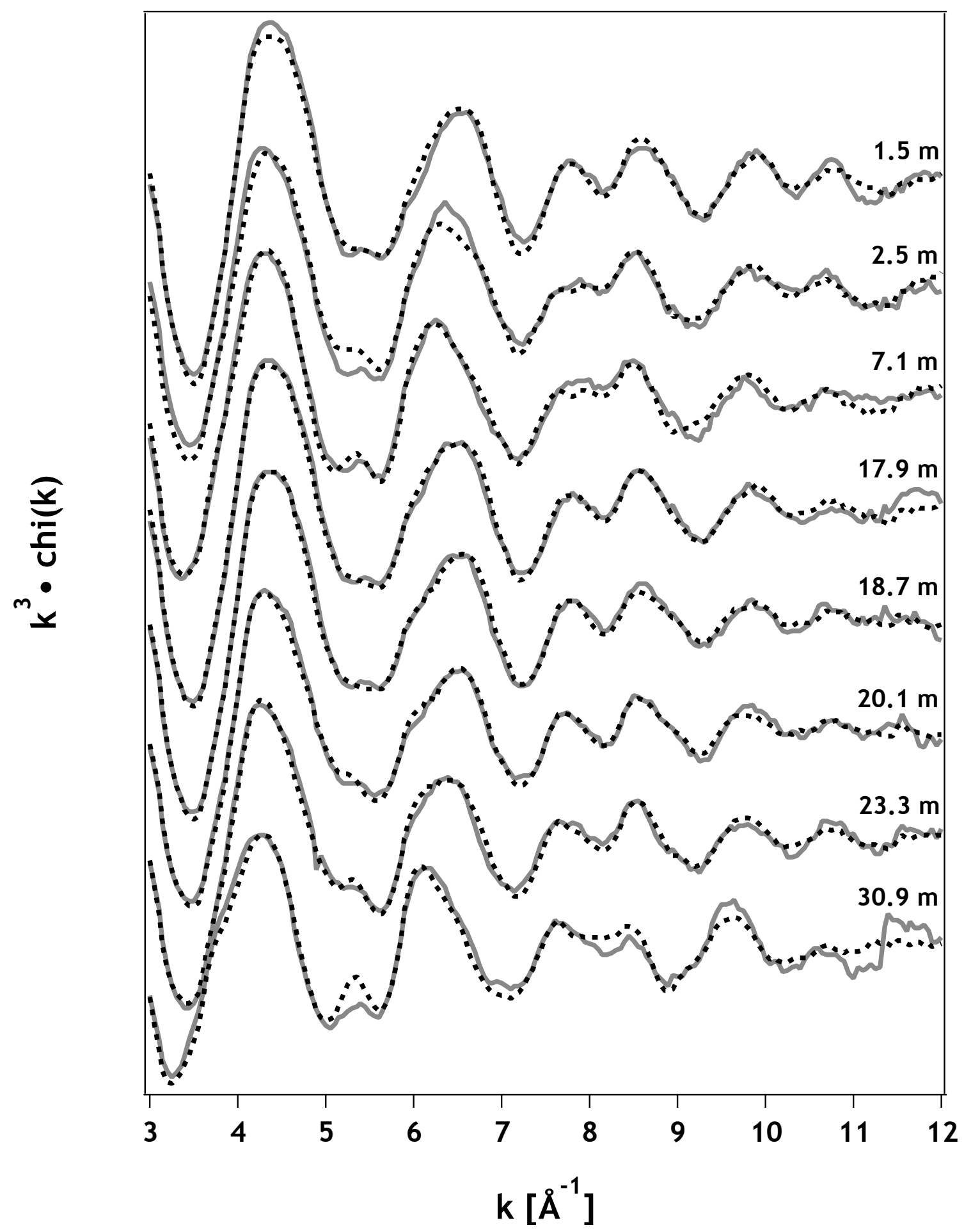

Figure 5. Fe K-edge EXAFS spectra (solid lines) and least squares fit results (dashed lines) for sediment samples collected between 1.5 and $30.9 \mathrm{~m}$ depth. 

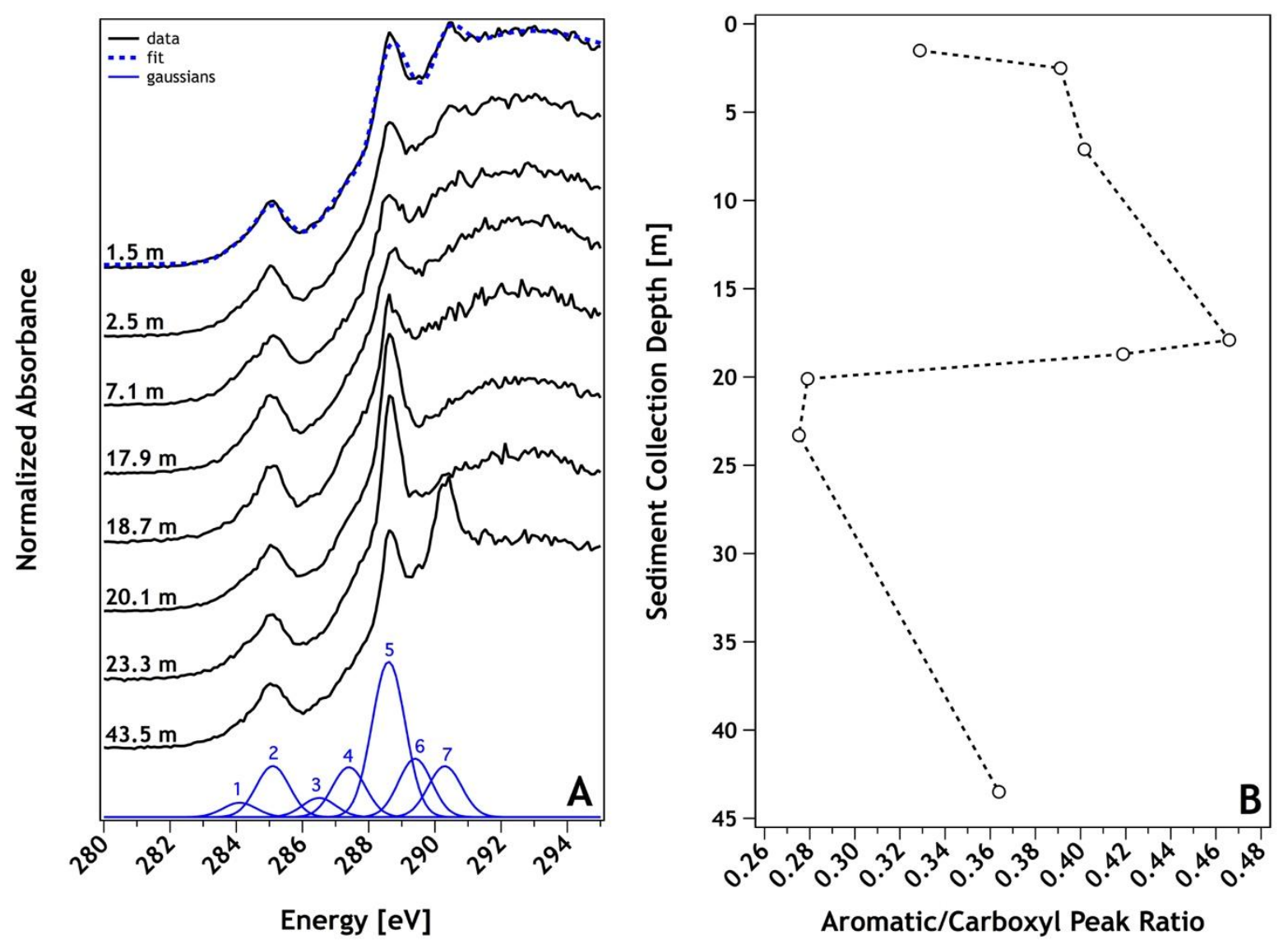

Figure 6. Carbon near-edge X-ray absorption fine structure (NEXAFS) spectra of sediments collected from 1.5 to $43.5 \mathrm{~m}$ below ground level. (a) Normalized fluorescence spectra for sediment at eight depths. Solid black lines are data. Solid blue lines show Gaussian peak positions used to fit all spectra. Peak heights shown are the solution of the least-squares fit for sediment at $1.5 \mathrm{~m}$ depth, and the fit is shown overlaid on the $1.5 \mathrm{~m}$ spectrum as dashed blue lines. Peak numbers correspond to the following moieties: 1 quinone, 2 aromatic, 3 phenolic, 4 aliphatic, 5 carboxyl/amide, 6 O-alkyl, 7 carbonate. (b) The ratio of peak height of aromatic $(285.1 \mathrm{eV})$ to carboxyl/amide $(288.6 \mathrm{eV})$ peaks describe the aromaticity of sediment samples as a function of sediment depth. 


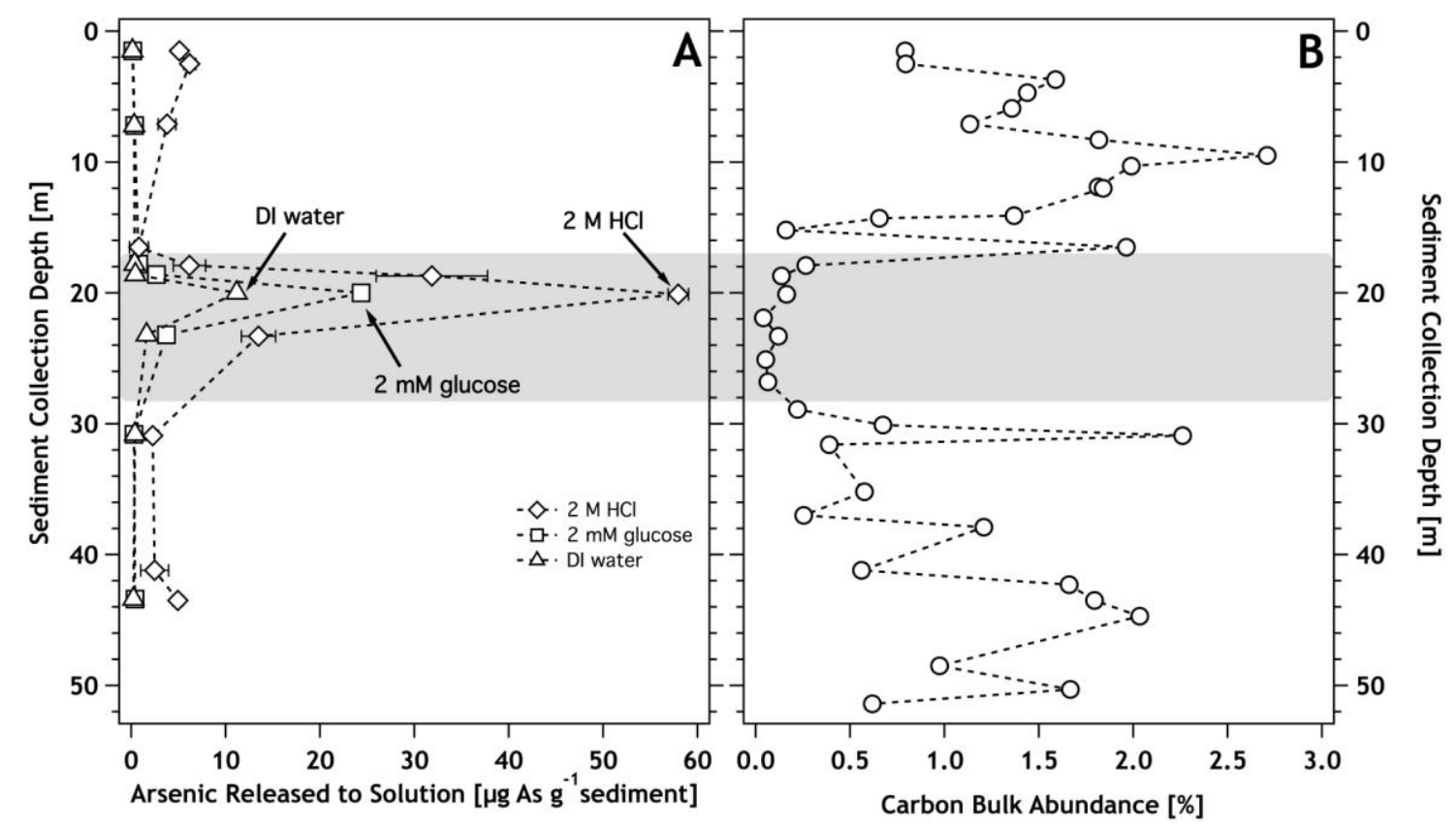

Figure 7. (a) Arsenic release to solution in batch incubations with deionized water, $2 \mathrm{mM}$ glucose, or extraction in $2 \mathrm{M} \mathrm{HCl}$. Arsenic concentrations ( $\mathrm{DI}$ and $2 \mathrm{mM}$ glucose; average of duplicates) batch reactors were measured after 4 days of incubation at $25^{\circ} \mathrm{C}$. $\mathrm{HCl}$ extractions were performed in triplicate. (b) Carbon bulk abundance as a function of sediment collection depth. The grey box highlights the increase in As release where bulk $\mathrm{C}$ content is at a minimum. 

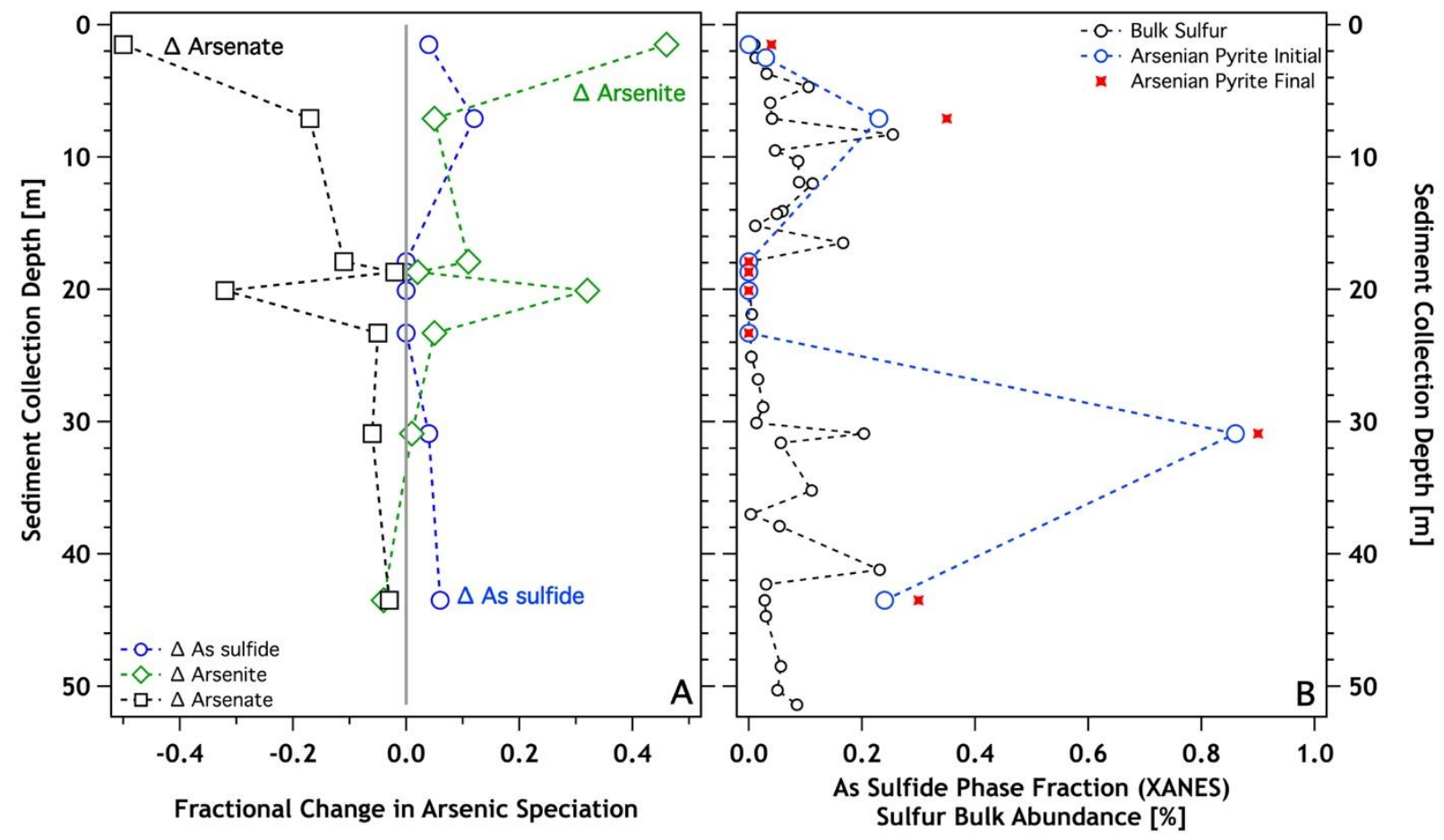

Figure 8. (a) Change in solid phase arsenic speciation after batch incubation of sediment with 2 $\mathrm{mM}$ glucose for 4 days. Differences are determined by comparing the results of As K-edge XANES linear combination fits (LCF) determined on native sediment to LCF of sediment incubated in batch reactors with glucose. (b) Bulk sulfur concentration as a function of sediment collection depth (black circles) and As sulfide fraction of native sediment (blue circles). Red symbols indicate the As sulfide fraction determined by LCF after glucose incubation. The difference between the blue circle and the red $x$ at a given depth result in the data shown in panel A. 


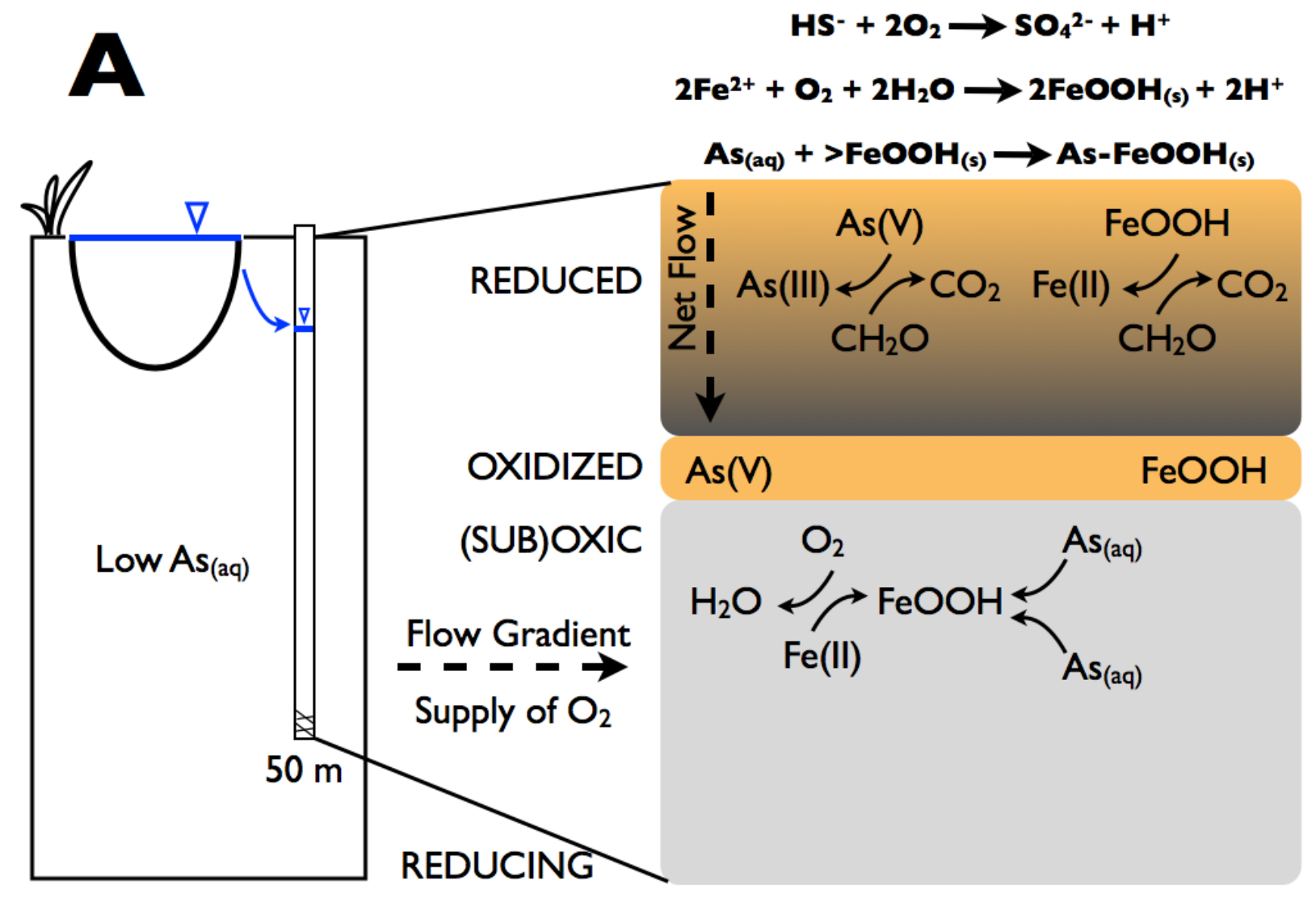




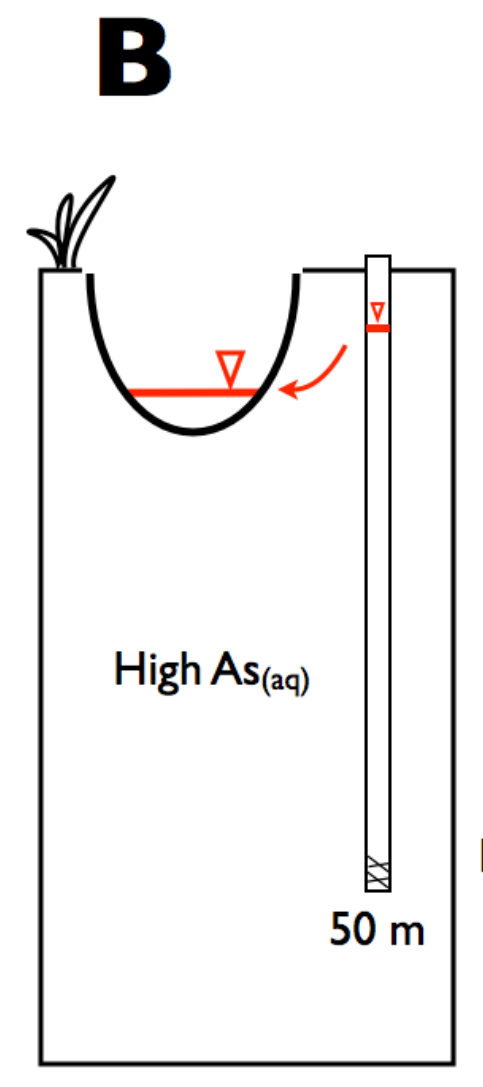

$$
\begin{aligned}
& \mathrm{CH}_{2} \mathrm{O}+4(\mathrm{As}) \mathrm{FeOOH}_{(\mathrm{s})} \underset{\mathrm{HCO}_{3}^{-}+4 \mathrm{Fe}^{2+}+2 \mathrm{H}^{+}}{\longrightarrow} \\
& 2 \mathrm{CH}_{2} \mathrm{O}+\mathrm{SO}_{4}{ }^{2-} \rightarrow 2 \mathrm{HCO}_{3}^{-} \mathrm{HS}^{-}+\mathrm{H}^{+}
\end{aligned}
$$
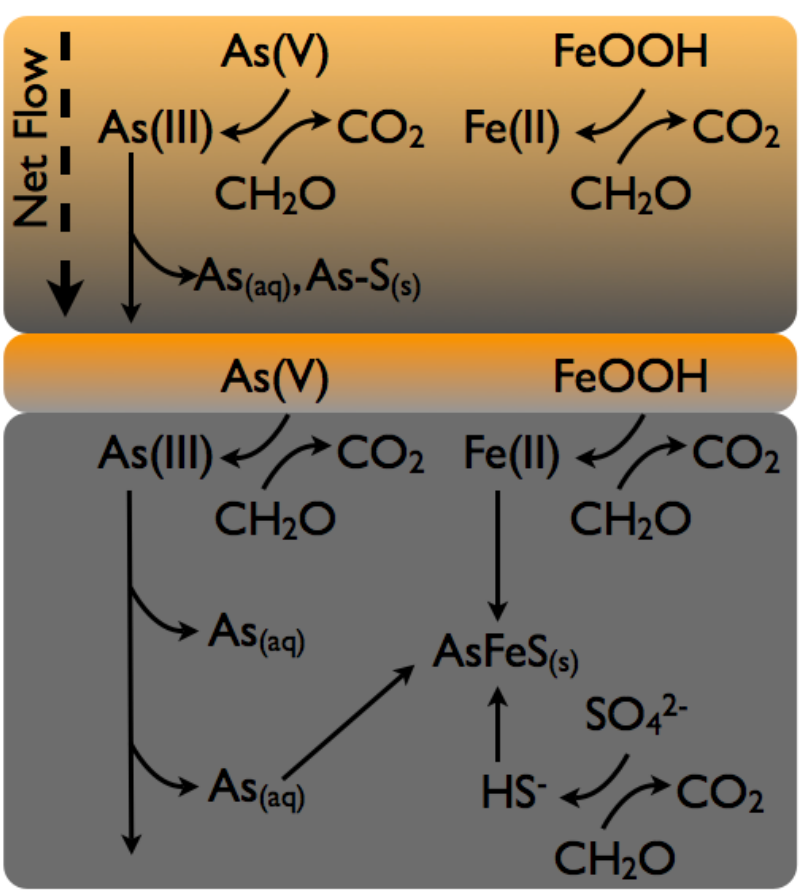

Figure 9. Schematic diagram of the dominant redox processes occurring during (a) groundwater recharge and (b) groundwater discharge. 